UNIVERSIDADE DE BRASÍLIA

Curso de Especialização em Gestão Universitária

Programa de Pós - Graduação em Administração/UnB PPGA

\title{
OS PROFESSORES PELOS ALUNOS - UMA AVALIAÇÃO DOS DOCENTES DA UnB
}

GABRIELA THAMARA DE FREITAS BARROS

BRASÍLIA

JUNHO, 2010 


\section{OS PROFESSORES PELOS ALUNOS - UMA AVALIAÇÃO DOS DOCENTES DA UnB}

Monografia apresentada no curso de Gestão Universitária do Programa de Pós-Graduação em Administração da Faculdade de Economia, Administração, Contabilidade e Ciência da Informação e Documentação (FACE), da Universidade de Brasília, como requisito à obtenção do grau de Especialista em Gestão

Universitária

Orientadora:

Profa. Dra. Maria Julia Pantoja Britto

BRASÍLIA

JUNHO, 2010 
Aos meus pais, familiares e amigos, que sempre estiveram comigo, me oferecendo incondicional apoio, incentivo e amor.

Á minha mãe pela dedicação e interesse pelo meu trabalho.

À minha orientadora que estendeu a mão no momento que mais precisei.

5 


\section{RESUMO}

O presente trabalho tem como objetivo avaliar o grau de satisfação dos alunos da UnB em relação ao desempenho dos docentes no que se refere às práticas pedagógicas e relacionamento com os alunos. Além disso, por meio da análise dos bancos de dados dos diversos anos avaliados, verificar a ocorrência de elevação ou redução do grau de satisfação dos alunos sobre os aspectos mencionados ao longo do tempo. Para tanto, foram utilizadas as respostas dos alunos da Universidade de Brasília ao instrumento que avalia o desempenho do professor nas diversas disciplinas ministradas semestralmente. As análises partiram das respostas dos alunos sobre os itens que compõem a segunda seção do instrumento: desempenho do professor. As questões foram analisadas separadamente e simulações foram feitas visando obter clusters em que o padrão de respostas dos alunos fossem semelhante dentro dos clusters e diferentes entre os clusters. Verificou-se que não existe diferença em pontos percentuais entre os períodos avaliados e que existem pontos fortes e a melhorar apontados pelos alunos. E, além disso, que a maioria dos alunos da universidade está muito satisfeita e satisfeita com o desempenho dos docentes no que tange às práticas pedagógicas e relacionamento.

Palavras chave: avaliação docente, satisfação, cluster. 


\section{SUMÁRIO}

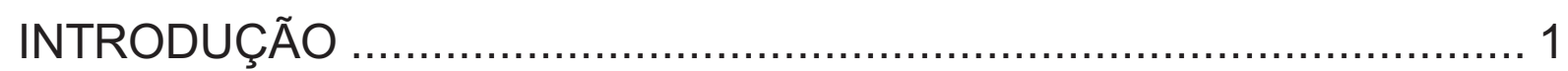

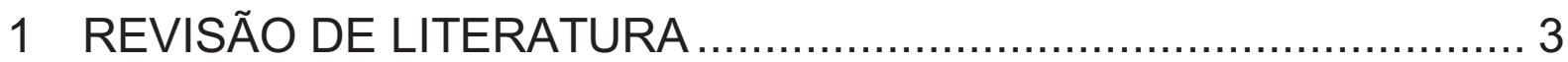

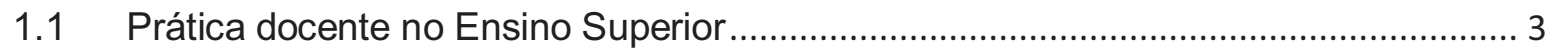

1.2 Importância e principais conceitos na área de avaliação ........................................... 4

1.3 Medidas para avaliação de desempenho ................................................................. 6

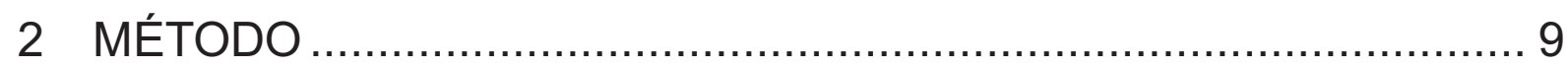

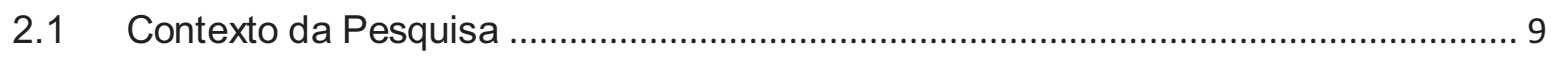

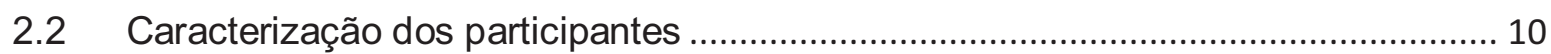

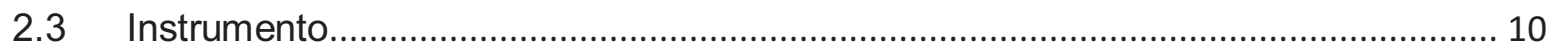

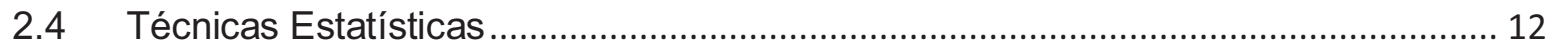

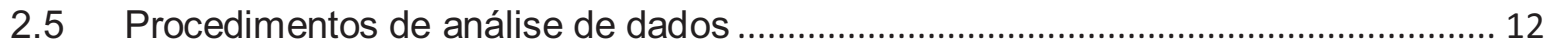

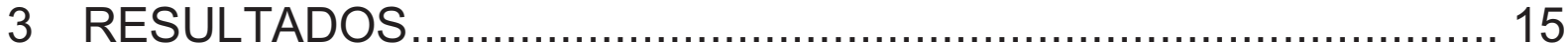

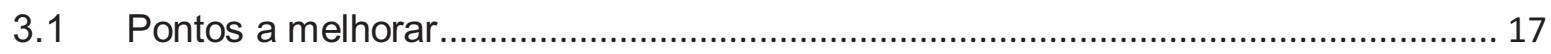

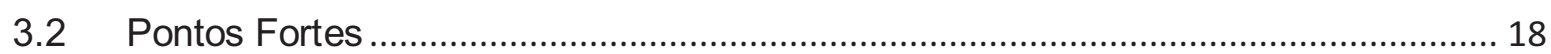

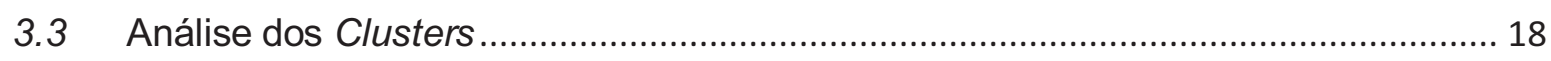

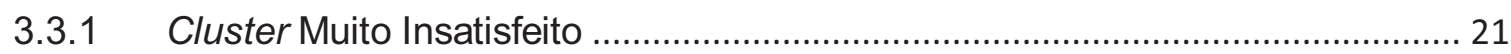

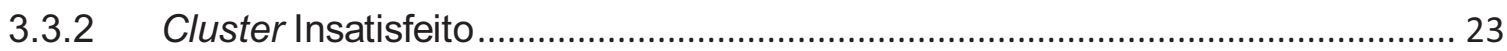

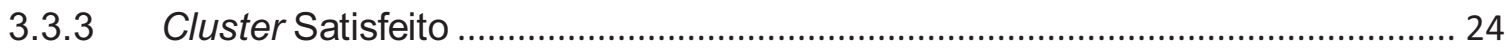

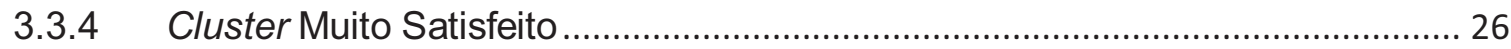

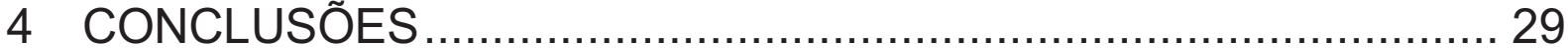

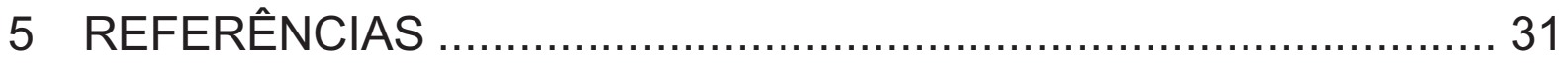

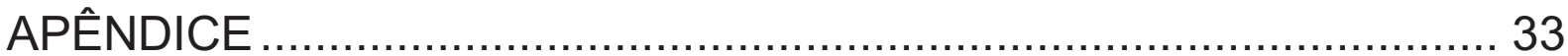

Apêndice A - tabelas cluster muito insatisfeito .................................................................... 33

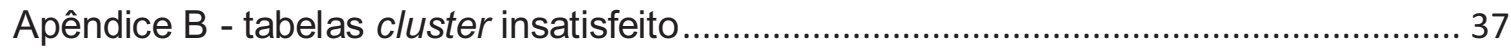

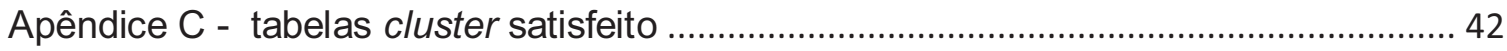

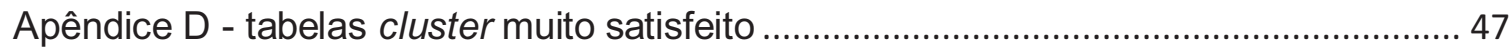

ANEXO A - AVALIAÇÃO DE DISCIPLINA PELO ALUNO .................. 54

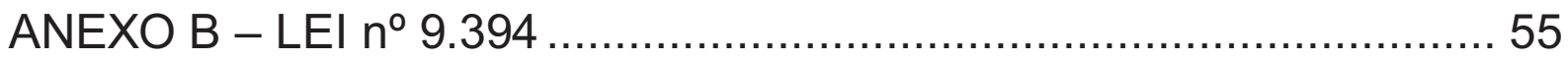




\section{INTRODUÇÃO}

Atualmente o tema educação tem sido bastante discutido e diversas medidas vêm sendo tomadas nas universidades brasileiras, especialmente com vistas a ampliar o acesso à educação.

Nessa perspectiva, Marilena Chauí (2003), argumenta que tais medidas estão sendo vistas a olho nu. São elas: o aumento de horas-aula, a diminuição do tempo para mestrados e doutorados, a avaliação pela quantidade de publicações, colóquios e congressos, a multiplicação de comissões e relatórios, etc. Para a autora, a docência é entendida como transmissão e adestramento. Desapareceu a marca essencial da docência que é o processo de formação dos professores.

Ao mencionar a reforma da universidade, a referida autora considera que um dos fatores que promoveriam a melhora na educação depende do professor conseguir realizar permanentemente seu processo de formação e de atualização dos conhecimentos e das técnicas pedagógicas.

No que se refere a Universidade de Brasília, sua reestruturação e expansão foram definidas pelos colegiados, de acordo com o documento do Projeto REUNI, enviado para o Ministério da Educação em dezembro de 2007. Tal medida foi tomada para atender as crescentes demandas por oferta de ensino superior para a população do Distrito Federal e entorno.

São previstas na UnB a criação de 3424 vagas nos novos cursos e o aumento de 892 vagas nos cursos existentes até 2012, nos campi Darcy Ribeiro, Planaltina, Gama e Ceilândia. Ainda, contará com a construção de novos prédios, melhoria e reforma da atual infra-estrutura, construção de novos laboratórios, contratação de novos professores e técnicos - administrativos, além de adequações nos currículos acadêmicos, conforme projeto apresentado pelo REUNI - Plano de Reestruturação e Expansão das Universidades Federais ao Ministério da Educação.

Tendo em vista as discussões sobre o REUNI, no sentido de reestruturar as universidades para que estas possam acompanhar as novas demandas. E ainda, as mudanças previstas na UnB e o que tem sido verificado como prática docente nas universidades, esse trabalho pretende analisar, e discutir com base em dados empíricos como os alunos da Universidade de Brasília estão avaliando seus docentes. 
Além disso, pretende-se avaliar se problemas referentes às práticas pedagógicas estão sendo percebidos pelos alunos e influenciando na avaliação destes quanto ao desempenho dos docentes.

Assim, o objetivo central desse estudo é avaliar a satisfação dos alunos da UnB com seus docentes no que se refere a práticas pedagógicas e relacionamento com os alunos. Além disso, por meio da análise dos bancos de dados dos diversos anos avaliados, verificar se a avaliação dos alunos sobre seus docentes está aumentando ou diminuindo no decorrer do tempo considerado.

Esse estudo se reveste de importância para os gestores da Universidade e para os professores na medida em que fornece um panorama geral da satisfação dos alunos e indica medidas que podem ser tomadas para melhorar a satisfação destes com o desempenho dos docentes. Aliado a isso, fornece subsídios úteis para identificação e análise das necessidades dos alunos, bem como oportunidade de uma reflexão sobre as práticas atuais, novas visões e, conseqüentemente, novas propostas de atuação na área da docência de ensino superior.

O trabalho esta estruturado em quatro seções. A primeira apresenta a revisão de literatura em que o estudo está fundamentado. A segunda seção descreve a metodologia utilizada bem como o contexto da pesquisa. Em seguida os resultados são discutidos e por fim é feita a conclusão do estudo. 


\section{REVISÃO DE LITERATURA}

\subsection{Prática docente no Ensino Superior}

Em face às novas realidades educacionais, discussões sobre a qualidade da educação, sobre a formação dos educadores e relações interpessoais entre professores e alunos, são cada vez mais presentes na educação superior.

Assim a docência não é mais entendida como apenas o ato de ministrar aulas. Segundo Libâneo (2007), trata-se de uma valorização da atividade pedagógica em sentido mais amplo, na qual a docência está incluída.

Vasconcelos (2005), reforça a importância dessas discussões ao ressaltar a relevância dos docentes para a transformação da qualidade social da escola, pois estes colaboram para transformar a gestão, os currículos, a organização, os projetos educacionais e as formas de trabalho pedagógico. Sendo assim, desenvolvimento profissional e qualidade de vida no trabalho podem estar relacionados com a melhora na qualidade social da escola, já que estes transformam a forma com que o docente percebe sua profissão.

Elton e Partington, (1991, apud Abrantes \& Valente 1988), de um modo geral caracterizam o perfil do docente do ensino superior em 15 categorias. Dessas categorias 10 são inerentes ao ensino da instituição e 5 critérios externos. As categorias inerentes ao ensino são:

- preparação para o ensino;

- qualidade do ato de ensinar;

- volume do ensino; inovação;

- comunicação geral com os alunos fora das aulas;

- procedimentos de avaliação;

- $\quad$ avaliação do próprio ensino;

- gestão do ensino;

- melhoria e investigação do próprio ensino; e

- ensino e envolvimento com o mundo do trabalho.

Com relação às categorias inerentes aos critérios externos, são enfocados: 
- convites para ensinar fora da instituição;

- pertencer a grupos profissionais;

- serviços prestados noutras universidades;

- organizações sobre o ensino; e

- bolsas/contratos para desenvolvimento de trabalhos para outras instituições.

Nessas 15 categorias citadas percebe-se que muitas estão relacionadas com as práticas pedagógicas, como por exemplo, inovação, procedimentos de avaliação, gestão do ensino, etc.

Com isso, a "reciclagem" constante do docente é importante para tentar sanar a carência do professor na aérea pedagógica, uma vez que, o domínio de didática é importante para o dia a dia na sala de aula e torna-se um facilitador no processo de ensino aprendizagem, conforme salienta Ferreira (2010).

O referido autor menciona que para o exercício pleno da docência, o profissional deve possuir algumas habilidades básicas, tais como: pesquisa, domínio na área pedagógica, didática, trabalhar em equipe, seleção de conteúdos, desenvolvimento de atividades multidisciplinares e principalmente, saber integrar no processo de aprendizagem o desenvolvimento cognitivo e afetivo-emocional. Além disso, enfatiza que o papel do docente requer a utilização de estratégias para facilitar a aprendizagem dos alunos.

Em geral pode-se observar a valorização das qualificações acadêmicas, pesquisas e titulações e ainda pouca atenção às qualificações pedagógicas e interpessoais. Isso pode ser constatado na lei, em anexo, $n^{\circ}$ 9.394, de 20 de dezembro de 1996, capitulo IV Art. 43, que estabelece as diretrizes e bases da educação nacional.

\subsection{Importância e principais conceitos na área de avaliação}

Avaliar deriva de valia, que significa valor. Para Silva (1992), a todo o momento o ser humano avalia os elementos da realidade que o cerca. O processo de avaliação é uma exigência atual da sociedade e é uma forma de monitorar programas para garantir efetividade nas organizações. 
Conforme Garcia, 2001, avaliar compete analisar o valor de algo em relação a algum anseio ou a um objetivo, não sendo possível avaliar, consequentemente, sem se dispor de uma referência, de um quadro referencial razoavelmente preciso. Assim, é preciso estar consciente que aspectos ligados ao desenvolvimento pessoal e social do avaliando e do avaliado influenciam de alguma forma no comportamento e na avaliação que é feita.

As situações de avaliação não devem ser isoladas, mas sim, devem fazer parte de um processo; medidas devem ser subsidiadas por análise de contexto, cultura organizacional e pesquisa socioeconômica.

Segundo Tonello (2010), na avaliação o foco não deve recair sobre a avaliação de produtos, mas sim na reflexão qualificada sobre os processos e percursos de aprendizagem. Torna-se necessário, portanto, modificar o foco do que olhar: ao invés de observar apenas o produto da aprendizagem, que são as respostas finais dadas pelos alunos, é necessário analisar o processo, isto é, as estratégias usadas para enfrentar os desafios.

Vários modelos de avaliação foram delineados visando aferir os resultados de programas institucionais. A definição desses modelos está diretamente relacionada ao momento em que a coleta de dados é realizada. Tais modelos podem ser classificados como formativos ou normativos. No que diz respeito a avaliação somativa, pressupõe que a coleta de dados seja realizada ao final do processo instrucional, com o intuito de verificar a capacidade deste de produzir resultados. Já na avaliação formativa, a coleta de dados ocorre ao longo do processo, de modo contínuo, e o intuito é fornecer dados para tomada de decisão na tentativa de criar condições de melhoria de ensino e de aprendizagem, uma vez que o processo não foi encerrado.

O modelo CIPP de Stufflebeam (1983), por exemplo, prevê quatro tipos de avaliação:

- Contexto, na qual se assentam as decisões de planejamento;

- Insumo, que projeta e analisa esquemas alternativos de procedimentos, fundamentando decisões de estruturação;

- Processo, que acompanha etapas de implementação;

- Produtos, que aprecia resultados, fundamentando decisões de reciclagem. 
Por fim, Pestana (1988), no que se refere aos aspectos do processo de avaliação e controle, recorda os seguintes princípios:

- Visibilidade Social: prestação de contas a todos os envolvidos nos programas de forma a identificar e apresentar os resultados e os produtos obtidos, sinalizando os caminhos que ainda devem ser percorridos;

- Responsabilidade compartilhada, no sentido de identificar a parcela de contribuição de cada segmento envolvido na obtenção de resultados;

- Legitimidade, de forma que a sistemática de avaliação esteja sustentada em apresentação clara das regras estabelecidas;

- Continuidade, o que indica que o sistema de avaliação deve repetir em novos ciclos de aplicação;

- Qualidade, medida de rendimento, expresso em termos de aprendizagem, competência ou habilidades adquiridas.

Sintetizando, a avaliação tem que ser entendida como uma das etapas de um processo complexo que visa à busca pela qualidade e excelência do sistema de ensino-aprendizagem. Sendo assim, ela não se justifica de forma isolada e precisa ser feita de forma continua e padronizada. Diante disso, será abordado a seguir, o papel relevante da construção e desenvolvimento de medidas de avaliação.

\subsection{Medidas para avaliação de desempenho}

Criar uma medida de avaliação é um processo complexo, pois abrange não só a criação de um instrumento de pesquisa e utilização de uma técnica estatística, mas também discussões sobre o que dever ser avaliado com todos os atores do processo, contexto social dos avaliandos e avaliados, período e logística de aplicação, impacto dos resultados, divulgação a todos envolvidos no processo, etc.

Além disso, é preciso focar em como os resultados serão apresentados e como eles poderão contribuir para o processo de aprendizado visando melhorias no ensino. É importante indicar não apenas um número que reflita intensidade, média das notas atribuída pelos alunos, por exemplo, e sim o que é necessário ser feito 
para alcançar a melhoria e quais são as práticas que não precisam ser alteradas por estarem sendo bem avaliadas.

É importante para um docente ao receber um relatório de desempenho saber o que é esperado dele e o que é necessário ser feito para melhorar a satisfação dos seus alunos. Assim tais relatórios serão entendidos como um instrumento que pode gerar mudanças positivas em suas práticas e não simplesmente como um julgamento do seu trabalho.

Segundo Abrantes \& Valente (1988), a avaliação do trabalho dos docentes do Ensino Superior deve considera aspectos que são inerentes às suas funções e considerar os seguintes processos:

- exame do nível do trabalho, incluindo o pensamento sobre esse trabalho, as atividades, e as contribuições do docente;

- reflexão sobre a qualidade do trabalho e a discussão de padrões de desempenho com colegas, chefes, diretores;

- existência de feedback de outros esperando-se o seu uso para melhorar a qualidade do trabalho.

Os mesmos autores ao se referirem à continuidade do processo dizem que: "o ciclo da avaliação não deve terminar e necessita manter os docentes comprometidos em procurarem sentido para o seu próprio trabalho e partilhando com colegas e alunos sobre o mesmo, continuamente mudando e melhorando a partir da autoreflexão, diálogo e discussão."

No que se refere ao processo de avaliação de desempenho no trabalho, Odelius e Santos, 2007, enfocam aspectos que impactam na avaliação de desempenho e citando Levy e Williams (2004), fazem referência à variáveis distais e proximais. As variáveis distais, segundo tais autores pertencem a fatores contextuais e englobam fatores econômicos externos, avanços tecnológicos, composição e formação da força de trabalho, cultura da sociedade onde a organização está inserida. Já as proximais são àquelas que têm impacto direto na maneira como o processo de avaliação de desempenho é conduzido. Portanto, estão relacionadas com composição da avaliação e incluem itens como dimensões e critérios de avaliação, freqüência de realização, capacitação específica para o processo avaliativo, documentação utilizada, entre outros. Desta forma, ao elaborar um relatório de 
desempenho é necessário considerar as particularidades do processo e as variáveis que impactam nesta avaliação.

Assim, para garantir uma avaliação eficaz é necessário garantir medidas fidedignas e confiáveis para avaliar o desempenho no trabalho.

Na próxima seção são apresentados os procedimentos metodológicos adotados na pesquisa bem como o contexto da pesquisa. 


\section{MÉTODO}

\subsection{Contexto da Pesquisa}

Utilizou-se nesse trabalho as respostas dos alunos da Universidade de Brasília ao instrumento que avalia o desempenho do professor nas diversas disciplinas ministradas, semestralmente no âmbito das diversas unidades acadêmicas.

Para a realização deste estudo foi utilizado parte dos resultados da avaliação discente da Universidade de Brasília realizada nos anos de 2003 e 2006 a 2009. Inicialmente o intuito era analisar todos os semestres de 2003 a 2009, porém, observou-se que os questionários dos períodos não analisados eram diferentes dos questionários dos períodos analisados neste trabalho.

Essa avaliação é uma ação institucional da Universidade que ocorre semestralmente e que visa avaliar a percepção dos alunos sobre os cursos que concluem. O instrumento utilizado na avaliação discente da UnB é dividido em cinco seções de itens objetivos: programa da disciplina; desempenho do professor; autoavaliação de rendimento e suporte à execução da disciplina, além de um item aberto relativo aos pontos fortes e a melhorar do professor.

Quanto a coleta de dados, é importante ressaltar que o questionário é entregue às secretarias e este é distribuído no final do curso. Não existe um controle efetivo da aplicação e em algumas situações a responsabilidade de aplicar e devolver os questionários pode recair sobre os próprios professores.

Além disso, os resultados não podem ser extrapolados para todos os alunos da UnB, já que o processo de coleta é uma tentativa de censo e não foi feito nenhum controle da não resposta.

Assim, é necessário destacar a necessidade de aprimorar o processo avaliativo com vistas a assegurar a precisão e qualidade dos resultados da avaliação; e, prioritariamente, o cuidado com conclusões equivocadas.

Entretanto, tal trabalho tem sua validade, pois tem como finalidade dar um direcionamento aos gestores da universidade dos pontos forte e que precisam ser melhorados; da necessidade de discussão do tema; e subsidiar a elaboração de políticas de desenvolvimento e estruturação de programas para capacitação constante em práticas pedagógicas e relacionamento com os alunos. 


\subsection{Caracterização dos participantes}

O questionário foi respondido por alunos de todos os cursos de graduação da UnB que estavam em sala de aula na data da aplicação. Estes poderiam responder mais de uma vez o questionário, já que o questionário era aplicado por disciplina.

O banco de dados desse estudo foi composto de 211.586 respondentes ao questionário. A seguir, Tabela 2.2.1, quantitativo de respondentes por ano e semestre avaliado.

Tabela 2.2.1: Quantitativo de respondentes por ano e semestre

\begin{tabular}{l|c}
\hline Ano_Semestre & Número Alunos \\
\hline 2003_01 & 37.649 \\
2006_02 & 25.495 \\
2007_02 & 35.589 \\
2008_01 & 32.441 \\
2008_02 & 37.316 \\
2009_01 & 43.096 \\
Total & 211.586 \\
\hline
\end{tabular}

\subsection{Instrumento}

O instrumento utilizado é composto por 21 itens que avaliam o nível de satisfação dos alunos com práticas pedagógicas adotadas pelos professores e sobre o relacionamento com os alunos. Os alunos deveriam indicar, em uma escala de 0 a 10 , a sua satisfação com relação a cada item perguntado, sendo "0" equivalendo a muito insatisfeito e "10" equivalendo a muito satisfeito.

A seguir, são especificados os itens que os alunos deveriam avaliar em relação ao seu docente.

- Q1 - Domínio do conteúdo ministrado.

- Q2 - Qualidade na transmissão do conteúdo.

- Q3 - Entusiasmo demonstrado na transmissão do conteúdo. 
- Q4 - Incentivo à participação dos alunos nas atividades previstas no programa da disciplina.

- Q5 - Incentivo, ao aluno, à realização de atividades adicionais de aprofundamento do aprendizado.

- Q6 - Uso de estratégias para motivar os alunos em relação ao conteúdo.

- Q7 - Ritmo de apresentação do conteúdo.

- Q8 - Adequação das atividades desenvolvidas para o alcance dos objetivos propostos.

- Q9 - Profundidade com que o conteúdo foi abordado, considerando os objetivos da disciplina.

- Q10 - Integração do conteúdo da disciplina com conteúdos conexos de outras disciplinas.

- Q11 - Integração entre teoria, pesquisa e/ou aspectos da realidade.

- Q12 - Qualidade dos exemplos utilizados para relacionar teoria, pesquisa e prática.

- Q13 - Coerência entre nível de complexidade das avaliações (trabalhos, testes, provas, exercícios, etc) e o conteúdo ministrado.

- Q14 - Discussão dos resultados de avaliações de aprendizagem.

- Q15 - Adequação do uso dos recursos de ensino (quadro de giz, retroprojetor, etc).

- Q16 - Disponibilidade para esclarecer dúvidas e solucionar dificuldades dos alunos, relacionadas ao conteúdo da disciplina.

- Q17 - Cordialidade na relação com os alunos.

- Q18 - Respeito às idéias manifestadas pelos alunos acerca dos temas abordados.

- Q19 - Disponibilidade para atendimento extraclasse.

- Q20 - Cumprimento dos horários de início e término das aulas, pelo professor.

- Q21 - Assiduidade. 


\subsection{Técnicas Estatísticas}

Segundo Bussab \& Morettin, 2004, quando se estuda uma variável, o maior interesse do pesquisador é conhecer o comportamento dessa variável, analisando a ocorrência de suas possíveis realizações. Uma medida útil para avaliar o comportamento das variáveis em estudo é utilizar a frequência de cada categoria em relação ao total. Essa medida possibilita a comparação das variáveis já que estas possuem o mesmo total, isto é, $100 \%$.

Outra técnica utilizada neste trabalho foi a Teoria de Resposta ao Item. A TRI é uma técnica estatística utilizada para calcular indicadores interpretáveis. Os modelos da TRI colaboram quando o intuito é medir características que não são observadas diretamente e sim são inferidas a partir de observações secundárias que estejam relacionadas a ela. Dessa forma, se o intuito é medir satisfação com o desempenho do professor, submete-se os alunos a um questionário que versa sobre essas características secundárias.

A TRI é definida como um conjunto de modelos matemáticos que procura representar a probabilidade de um indivíduo dar uma resposta certa a um item, em função dos parâmetros do item e da habilidade dos respondentes (Andrade, Tavares \& Valle, 2000). Desta forma, acredita-se que, quanto maior for a satisfação do aluno com o desempenho do professor, maior é a probabilidade dele endossar positivamente as perguntas do questionário.

O uso da TRI no Brasil está voltado predominantemente para a elaboração de índices de proficiência de alunos a partir de processos de avaliação educacional em ampla magnitude, muito embora o modelo permita a construção de indicadores para diversas finalidades, conforme Soares, 2005.

\subsection{Procedimentos de análise de dados}

As análises partiram das respostas dos alunos sobre os itens que compõem a segunda seção do instrumento: desempenho do professor. Esse recorte para as análises justifica-se pelos critérios que compõe esse estudo, isto é criar avaliar a satisfação dos alunos em relação ao desempenho do professor. 
O banco de dados desse estudo é composto de 211.586 respondentes ao questionário. Esse quantitativo foi obtido após a retirada dos indivíduos que apresentaram 1 ou nenhuma resposta ao questionário.

A validação e tratamento dos dados foram realizados nos softwares SPSS 16.0 e Excel 2007.

Uma medida útil para avaliar o comportamento das variáveis em estudo é utilizar a frequência de cada categoria em relação ao total. Essa medida possibilita a comparação das variáveis já que estas possuem o mesmo total, isto é, $100 \%$.

Então, para conhecer melhor o banco de dados em estudo foram feitas análises exploratórias de todas as questões. Observou-se que a opção "Não se aplica" corresponde à um percentual muito baixo dentro do banco de dados. Sendo assim, optou-se por agrupar essa alternativa com a não resposta. Neste trabalho as opções "não se aplica" e não resposta estão codificadas nas tabelas e gráficos como "mis".

Outra medida adotada, a partir da análise exploratória dos dados, foi de procurar a melhor forma de agrupar as respostas dos alunos. Esse procedimento foi adotado para facilitar as análises. Assim, os dados foram codificados da seguinte forma: respostas de "0 a 6", "7 e 8" e "9 e 10".

Com o intuito de obter uma medida de satisfação, observou-se por meio da técnica análise fatorial, utilizando-se o software SPSS 16.0, a unidimensionalidade ou predominância de um traço latente no conjunto de questões cujas respostas variavam de 0 a 10. A unidimensionalidade ou predominância de um traço latente é um dos pressupostos para dar validade à utilização do modelo da TRI aplicado nesse estudo.

Para calcular essa medida de satisfação por meio do software BILOGMG 3.0 é necessário dicotomizar os dados. Assim, cada item do questionário foi transformado em dois novos subitens: "satisfação é maior ou igual a 7?" e " satisfação é maior ou igual a 9?" gerando um novo banco de dados. Para respostas "sim" foi atribuído o código 1 e para "não", código 0. Desta forma quando a resposta para essas duas perguntas era "não" se inferiu que a satisfação estava entre 0 e 6. No Quadro 2.4.1, a seguir, exemplifica-se a dicotomização:

Quadro 2.4.1: Exemplo dicotomização das respostas ao questionário \begin{tabular}{l|l} 
Item 1 & Item 1.1 satisfação é maior ou
\end{tabular} Item 1.2 satisfação é maior ou 


\begin{tabular}{|l|l|l|}
\hline & igual a 7? & igual a 9? \\
\hline $\mathbf{0}$ & $\mathbf{0}$ & $\mathbf{0}$ \\
\hline $\mathbf{6}$ & $\mathbf{0}$ & $\mathbf{0}$ \\
\hline 7 & 1 & 0 \\
\hline 8 & 1 & 0 \\
\hline 9 & 1 & 1 \\
\hline 10 & 1 & 1 \\
\hline
\end{tabular}

Observa-se, no exemplo, que esses itens apresentam uma característica ordinal e pressupõe-se que é mais difícil responder "sim" para o item "satisfação maior ou igual a 9" do que para o item "satisfação maior ou igual a 7". O objetivo de trabalharse com o banco de dados nessa configuração é agregar mais informação às análises, ao invés de ter que dicotomizar toda a escala.

Outro pressuposto necessário para dar continuidade às análises é que os itens possuam correlação bisserial maior que 0,3 . Segundo Soares, 2005, correlação bisserial é uma medida que visa avaliar se um determinado item possui correlação significativa com o score bruto produzido pelo conjunto de itens. Nesse estudo todos os subitens apresentaram correlações bisseriais altas, em geral em torno de 0,9.

Para o cálculo dos indicadores utilizou-se o modelo logístico de 2 parâmetros, em que leva-se em conta a dificuldade do item e sua discriminação, isto é, quanto um item se diferencia dos outros. Os indicadores e correlações bisseriais foram calculados por meio do software BILOGMG 3.0.

Ao banco de dados cuja escala inicial variava de 0 a 10 foram incluídos os indicadores calculados. Algumas simulações foram feitas na tentativa de obter -se clusters em que o padrão de respostas dos alunos sejam semelhantes dentro dos clusters e diferentes entre os clusters. 


\section{RESULTADOS}

Nesta seção são apresentados os resultados da avaliação de desempenho dos docentes aplicada semestralmente na UnB. Inicialmente, é importante lembrar que esse processo possui particularidades na coleta de dados conforme ressaltado na seção anterior. Espera-se então que esses resultados não sejam entendidos de forma isolada e conclusiva e ainda, que sejam considerados aspectos contextuais na medida em que podem exercer efeitos sobre a efetividade do processo de avaliação.

Quando o intuito é gerar reflexão nos atores (alunos, professores e gestores) do processo, como pretende o presente estudo, não é suficiente apenas, por exemplo, conhecer os quantitativos de alunos satisfeitos e insatisfeitos. É importante saber, antes de tudo, quais são as questões mais fáceis de obter satisfação dos alunos e quais são as mais difíceis. Assim, é possível dar um feedback mais preciso em relação ao que pode ser melhorado prioritariamente e acompanhar o que está indo bem.

Conforme apresentado na Figura 3.1 a seguir, a suposição aqui adotada é de que questões cuja porcentagem de respondentes é alta para as categorias: "7 e 8" e "9 e 10" indicam que é mais fácil para os alunos avaliarem satisfatoriamente o professor, assinalando então um ponto forte. Já o contrário, questões cuja freqüência de respondentes for baixa para essas categorias, indicam dificuldade de avaliar positivamente os docentes, sendo definido como pontos a melhorar. Neste caso, existe a necessidade de se trabalhar tais pontos com os professores.

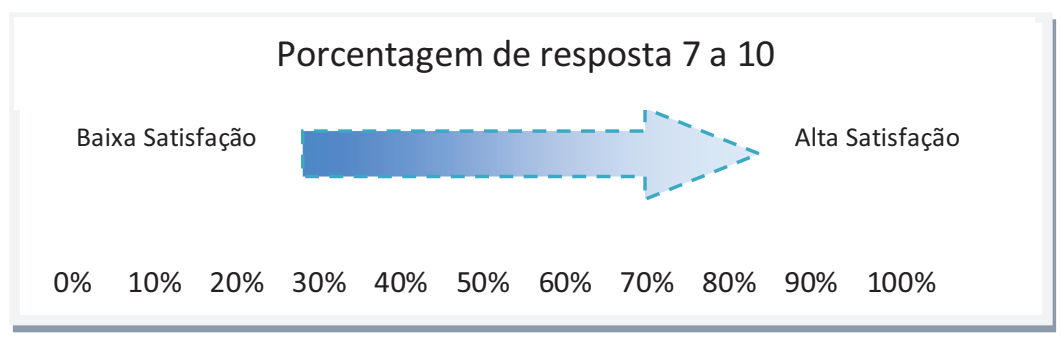

Figura 3.1: Grau de satisfação em relação ao docente de acordo com as respostas ao questionário

Não se observou diferença significativa em pontos percentuais entre os períodos analisados, conforme detalhado nas tabelas do apêndice. Sendo assim, as análises 
dos pontos a melhorar e fortes dos docentes serão apresentadas a partir do total de respondentes nesses períodos. A seguir, Gráfico $3.1 \mathrm{com}$ a distribuição das categorias por questão avaliada.

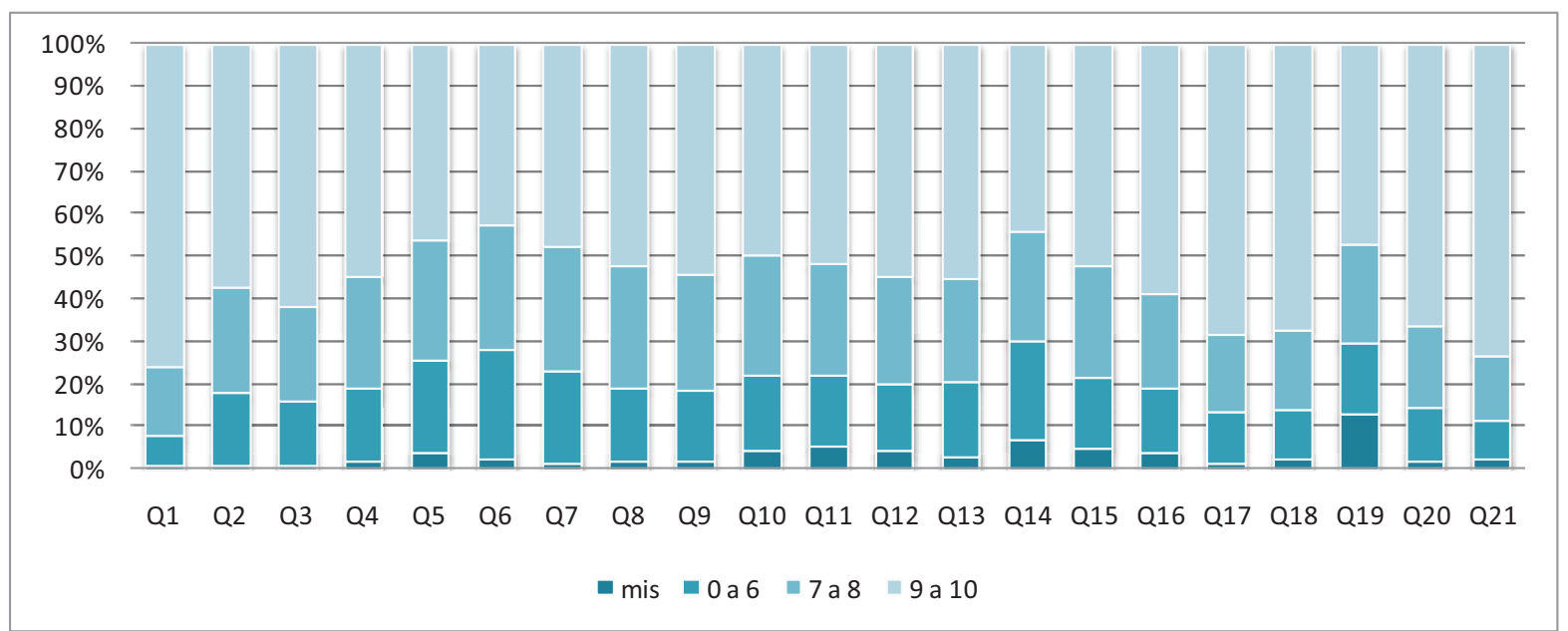

Gráfico 3.1: Distribuição das categorias por questão avaliada

Sendo:

Q1 - Domínio do conteúdo ministrado

Q2 - Qualidade na transmissão do conteúdo

Q3 - Entusiasmo demonstrado na transmissão do conteúdo

Q4 - Incentivo à participação dos alunos nas atividades previstas no programa da disciplina

Q5 - Incentivo, ao aluno, à realização de atividades adicionais de aprofundamento do aprendizado

Q6 - Uso de estratégias para motivar os alunos em relação ao conteúdo

Q7 - Ritmo de apresentação do conteúdo

Q8 - Adequação das atividades desenvolvidas para o alcance dos objetivos propostos

Q9 - Profundidade com que o conteúdo foi abordado, considerando os objetivos da disciplina

Q10 - Integração do conteúdo da disciplina com conteúdos conexos de outras disciplinas

Q11 - Integração entre teoria, pesquisa e/ou aspectos da realidade

Q12 - Qualidade dos exemplos utilizados para relacionar teoria, pesquisa e prática

Q13 - Coerência entre nível de complexidade das avaliações (trabalhos, testes, provas, exercícios, etc) e o conteúdo ministrado

Q14 - Discussão dos resultados de avaliações de aprendizagem

Q15 - Adequação do uso dos recursos de ensino (quadro de giz, retroprojetor, etc) Q16 - Disponibilidade para esclarecer dúvidas e solucionar dificuldades dos alunos, relacionadas ao conteúdo da disciplina

Q17 - Cordialidade na relação com os alunos

Q18 - Respeito às idéias manifestadas pelos alunos acerca dos temas abordados

Q19 - Disponibilidade para atendimento extraclasse

Q20 - Cumprimento dos horários de início e término das aulas, pelo professor

Q21 - Assiduidade 


\subsection{Pontos a melhorar}

A apresentação dos pontos a melhorar, isto é, questões mais difíceis de obter satisfação dos alunos em relação a seus professores, têm o intuito de dar indicativos para os gestores e professores quanto ao que pode ser melhorado e gerar reflexões sobre as atuais práticas.

A partir do gráfico da distribuição das categorias por questão avaliada é possível indicar os atributos que estão sendo menos bem avaliados pelos alunos. A seguir:

* Uso de estratégias para motivar os alunos em relação ao conteúdo;

* Discussão dos resultados de avaliações de aprendizagem;

* Incentivo, ao aluno, à realização de atividades adicionais de aprofundamento do aprendizado.

Com base nos resultados aqui encontrados observa-se que as questões que os alunos indicaram como pontos a melhorar dos seus docentes giram entorno do aprendizado e da forma como ele é medido.

Ferreira (2010) diz que um dos papeis do docente é de utilizar estratégias para facilitar a aprendizagem dos alunos. Desta forma, desenvolver eventos de capacitação com os docentes de forma a aperfeiçoar competências nessa área constitui uma alternativa necessária e importante com vistas a facilitar a aprendizagem dos alunos.

O levantamento de pontos a melhorar é uma forma de indicar objetivamente quais são as práticas em que há necessidade de aprimoramento por parte dos docentes. Como mencionado na revisão de literatura, quando o avaliado conhece claramente quais são os pontos que necessitam de melhoria em seu desempenho profissional eles podem compreender melhor a avaliação de desempenho como uma tentativa de gerar mudanças positivas em suas práticas e não como um julgamento do seu trabalho.

Cabe lembrar que de forma geral os alunos estão satisfeitos com os professores da Universidade. Essas questões são as que obtiveram, dentre as questões avaliadas, o menor nível de muita satisfação (notas 9 e 10), cerca de $45 \%$ e satisfação (notas 7 e 8 ) 23\%. 


\subsection{Pontos Fortes}

Já a apresentação dos pontos fortes, isto é, questões mais fáceis de obter satisfação, têm como principal objetivo destacar que existem pontos de excelência em relação aos docentes e que são pontos que precisam ser valorizados.

A partir do gráfico da distribuição das categorias por questão avaliada é possível indicar os atributos que estão sendo bem avaliados pelos alunos. A seguir:

$\checkmark$ Domínio do conteúdo ministrado;

$\checkmark$ Assiduidade;

$\checkmark$ Cordialidade na relação com os alunos;

$\checkmark$ Respeito às idéias manifestadas pelos alunos acerca dos temas abordados.

Nessas questões a proporção de muita satisfação é próxima de $70 \%$ e satisfação $17 \%$, correspondendo a $87 \%$ de avaliações positivas.

Os resultados levam a crer que, entre os atributos medidos, talvez esses sejam os que os docentes mais entendem como essenciais na sua profissão. Tais resultados ressaltam a necessidade dos docentes estarem conscientes sobre quais são os atributos que serão avaliados e qual é o seu real papel na universidade.

\subsection{Análise dos Clusters}

Após as análises de cada questão do questionário, o banco de dados em estudo foi dividido em clusters. Esse procedimento foi viabilizado a partir da técnica estatística da TRI, que para cada respondente foi atribuído um escore que refletia sua satisfação com o docente. Aos alunos com muita insatisfação foi atribuído um escore muito baixo, já aos alunos com muita satisfação o escore é alto.

O objetivo de utilizar essa técnica é medir o nível de satisfação geral dos alunos em relação a seus professores e não mais a satisfação por atributos avaliados no questionário. O que motivou essa a divisão foi o questionamento se existem, por exemplo, alunos que de forma geral estão muito insatisfeitos com os professores ou muito satisfeitos. 
Como mencionado na revisão de literatura é coerente supor que existe uma relação entre a satisfação dos alunos com o desempenho dos seus docentes nas práticas pedagógicas e o processo de aprendizagem.

Para tanto, foram feitas diversas simulações com intuito de alcançar, da melhor forma, os objetivos propostos. Foram obtidos 4 clusters:

- Muito insatisfeitos, corresponde aos alunos que atribuíram, na grande maioria das questões, notas de 0 a 6 aos 21 itens do questionário;

- Insatisfeitos, corresponde aos alunos que julgaram em sua maioria notas de 0 a 6 aos 21 itens, porém existe uma pequena proporção de notas 7 e 8;

- Satisfeitos, corresponde aos alunos que julgaram em sua maioria notas de 7 a 10 aos 21 itens;

- Muito satisfeitos, corresponde aos alunos que julgaram em sua grande maioria notas 9 e 10 aos 21 itens apresentados.

$\mathrm{Na}$ Tabela 3.3.1, a seguir, estão apresentados os quantitativos e proporção de respondentes por ano/semestre nos cluster estudados.

Tabela 3.3.1: Quantitativos e proporção de respondentes por ano/semestre nos cluster

\begin{tabular}{|c|c|c|c|c|c|c|c|c|c|c|}
\hline \multirow[t]{2}{*}{ Ano_Semestre } & \multicolumn{2}{|c|}{ Muito Insatisfeito } & \multicolumn{2}{|c|}{ Insatisfeito } & \multicolumn{2}{|c|}{ Satisfeito } & \multicolumn{2}{|c|}{ Muito Satisfeito } & \multicolumn{2}{|c|}{ Total } \\
\hline & $\mathrm{n}$ & $\%$ & $\mathrm{n}$ & $\%$ & $\mathrm{n}$ & $\%$ & $\mathrm{n}$ & $\%$ & $\mathrm{n}$ & $\%$ \\
\hline $2003 \quad 01$ & 3.020 & 8 & 7.929 & 21 & 18.712 & 50 & 7.988 & 21 & 37.649 & 100 \\
\hline 2006_02 & 1.491 & 6 & 4.133 & 16 & 12.478 & 49 & 7.393 & 29 & 25.495 & 100 \\
\hline 2007_02 & 1.916 & 5 & 5.467 & 15 & 17.164 & 48 & 11.042 & 31 & 35.589 & 100 \\
\hline 2008_01 & 1.644 & 5 & 4.658 & 14 & 15.559 & 48 & 10.580 & 33 & 32.441 & 100 \\
\hline 2008_02 & 1.830 & 5 & 5.465 & 15 & 17.859 & 48 & 12.162 & 33 & 37.316 & 100 \\
\hline 2009_01 & 2.054 & 5 & 6.083 & 14 & 20.717 & 48 & 14.242 & 33 & 43.096 & 100 \\
\hline Total & 11.955 & 6 & 33735 & 16 & 102.489 & 48 & 63.407 & 30 & 211.586 & 100 \\
\hline
\end{tabular}

É possível observa na Tabela acima e no Gráfico 3.3.1 a seguir, que no decorrer dos anos existe uma semelhança na proporção de respondentes por cluster.

Observa-se também que a proporção de alunos muito insatisfeitos é muito pequena, seguida pela proporção de alunos insatisfeitos que em geral é $16 \%$ das respostas do banco de dados. Já a proporção de alunos satisfeitos corresponde à maior parte dos respondentes em todo o banco, cerca de 50\%, seguido pelos alunos muitos satisfeitos com o desempenho do professor. Assim, todas as análises por cluster serão feitas com o quantitativo total do banco de dados. 


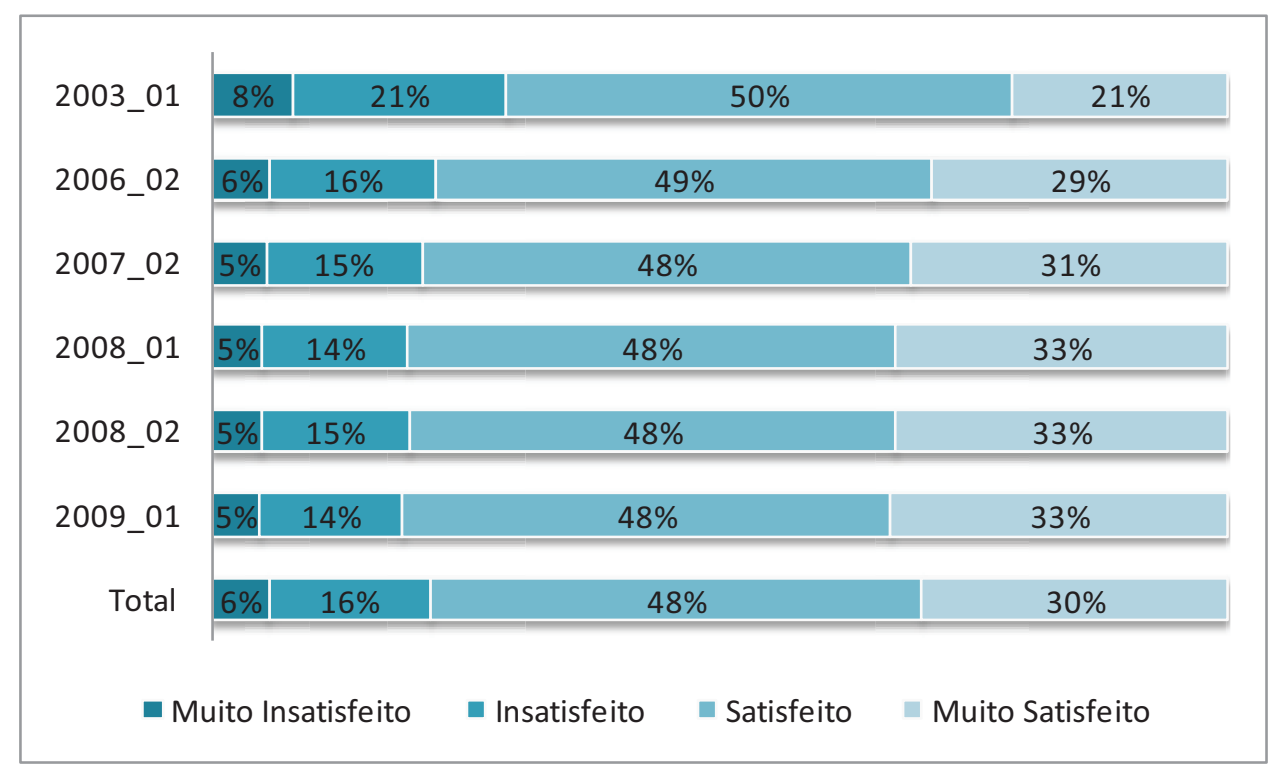

Gráfico 3.31 - Proporção de respondentes por ano/semestre e cluster.

Sendo assim, de acordo com os resultados do Gráfico 3.3.1, conclui-se, com base nas respostas dos alunos que responderam ao questionário, que estes estão em sua maioria muito satisfeitos ou satisfeitos com o desempenho dos professores da UnB e que menos de $30 \%$ estão muito insatisfeitos ou insatisfeitos.

Conclui-se também que o nível de satisfação dos alunos em relação aos seus docentes mantém-se de forma geral constante nos períodos avaliados, sinalizando que as alterações que estão sendo implementadas na universidade, no que se refere ao REUNI, ainda não estão sendo percebida pelos alunos nem negativamente nem de forma positiva.

Conhecer melhor esses clusters, isto é, a representatividade de cada cluster no universo estudado e o que os caracteriza em relação a pontos fortes e a melhorar, é uma forma de gerar reflexões e discussões na tentativa de melhorar cada vez mais a qualidade do ensino ofertado na universidade.

Nas próximas seções deste capítulo serão apresentados os resultados por cluster e suas particularidades. 


\subsubsection{Cluster Muito Insatisfeito}

Este cluster é formado pelos alunos que julgaram em sua grande maioria notas de 0 a 6 aos 21 itens do questionário e corresponde a $6 \%$ dos alunos que responderam aos questionários nos períodos em estudo. Cabe lembrar que apesar de proporcionalmente representar um valor muito baixo, em valores absolutos refere-se a 11.955 alunos que julgaram estar muito insatisfeitos com todas as práticas de seus docentes.

No Gráfico 3.3.1.1 é possível verificar que todas as questões obtiveram um bom ajuste a este cluster, já que a porcentagem de alunos que julgaram notas de 0 a 6 é bastante alta:

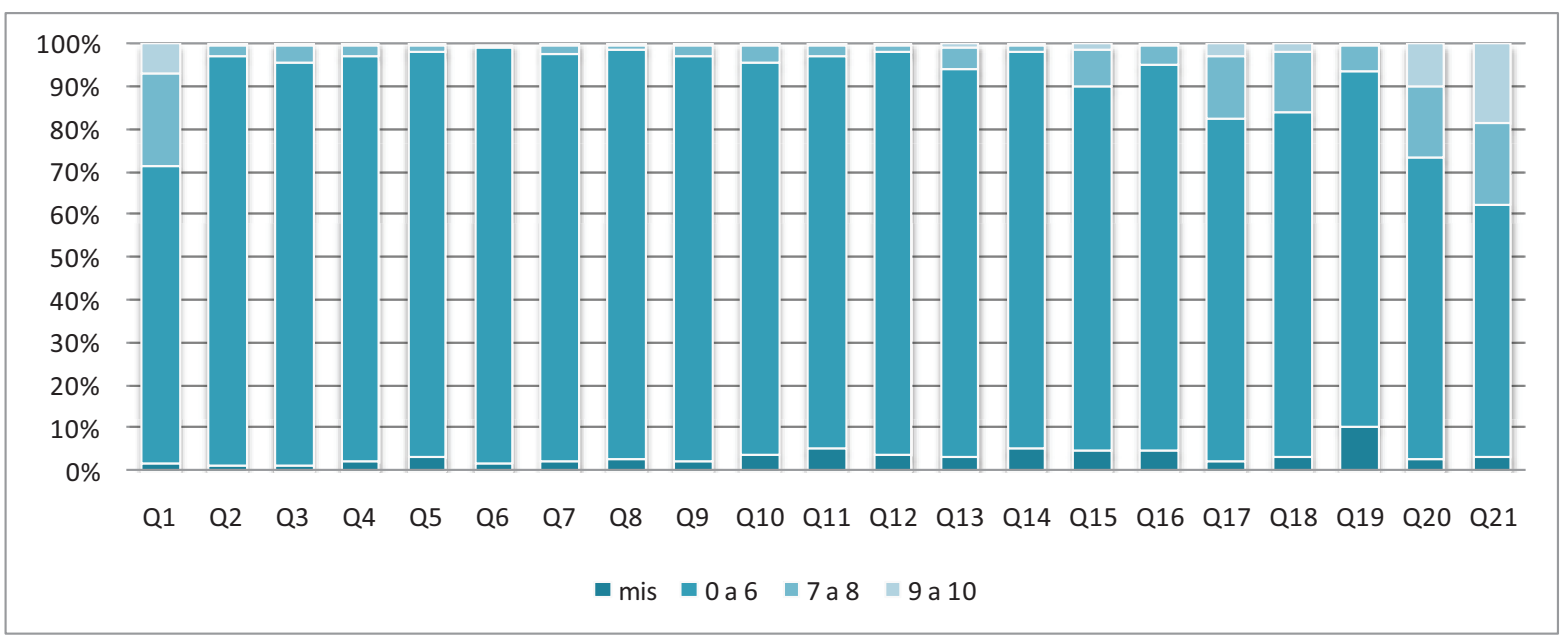

Gráfico 3.3.1.1 - Proporção de respondentes por questão no cluster alunos muito insatisfeitos

Sendo:

Q1 - Domínio do conteúdo ministrado

Q2 - Qualidade na transmissão do conteúdo

Q3 - Entusiasmo demonstrado na transmissão do conteúdo

Q4 - Incentivo à participação dos alunos nas atividades previstas no programa da disciplina

Q5 - Incentivo, ao aluno, à realização de atividades adicionais de aprofundamento do aprendizado

Q6 - Uso de estratégias para motivar os alunos em relação ao conteúdo

Q7 - Ritmo de apresentação do conteúdo

Q8 - Adequação das atividades desenvolvidas para o alcance dos objetivos propostos

Q9 - Profundidade com que o conteúdo foi abordado, considerando os objetivos da 
disciplina

Q10 - Integração do conteúdo da disciplina com conteúdos conexos de outras disciplinas

Q11 - Integração entre teoria, pesquisa e/ou aspectos da realidade

Q12 - Qualidade dos exemplos utilizados para relacionar teoria, pesquisa e prática

Q13 - Coerência entre nível de complexidade das avaliações (trabalhos, testes, provas, exercícios, etc) e o conteúdo ministrado

Q14 - Discussão dos resultados de avaliações de aprendizagem

Q15 - Adequação do uso dos recursos de ensino (quadro de giz, retroprojetor, etc)

Q16 - Disponibilidade para esclarecer dúvidas e solucionar dificuldades dos alunos, relacionadas ao conteúdo da disciplina

Q17 - Cordialidade na relação com os alunos

Q18 - Respeito às idéias manifestadas pelos alunos acerca dos temas abordados

Q19 - Disponibilidade para atendimento extraclasse

Q20 - Cumprimento dos horários de início e término das aulas, pelo professor

Q21 - Assiduidade

Mesma analogia, feita em relação a facilidade e dificuldade em obter satisfação dos alunos nos itens na análise geral, pode ser feita dentro dos clusters. Sendo assim, apesar desse cluster representar alunos muito insatisfeitos com os docentes, é possível destacar, dentre os 21 itens, quais são os itens que os alunos possuem um menor de grau de insatisfação e um maior grau de satisfação.

.A partir do gráfico 3.3.1.1, é possível indicar o atributo que está sendo menos bem avaliados pelos alunos. A seguir:

* Uso de estratégias para motivar os alunos em relação ao conteúdo.

Esse item é mais difícil de obter algum grau de satisfação dos alunos, pois, em geral, o percentual de notas de 0 a 6 , corresponde a $98 \%$ das respostas.

Da mesma forma, o item mais fácil de obter alguma satisfação dos alunos deste cluster são:

$\checkmark$ Assiduidade

$\checkmark$ Domínio do conteúdo ministrado

Tais atributos apresentam a menor porcentagem de muita insatisfação neste cluster, variando entre $60 \%$ a $70 \%$ das respostas. Sendo assim, dentro desse grupo essas questões podem ser consideradas as características mais fáceis de obter algum grau de satisfação dos alunos.

Interessante observa que os itens que são destacados como fáceis ou difíceis de obter satisfação nesse cluster são destacados também nas análises gerais. 


\subsubsection{Cluster Insatisfeito}

Neste cluster os itens em geral possuem uma alta proporção de notas de 0 a 6 e existe uma pequena proporção de notas 7 e 8 . Este cluster representa $16 \%$ dos respondentes do banco de dados.

A seguir Gráfico 3.3.2.1 com a proporção de respostas para cada item avaliado.

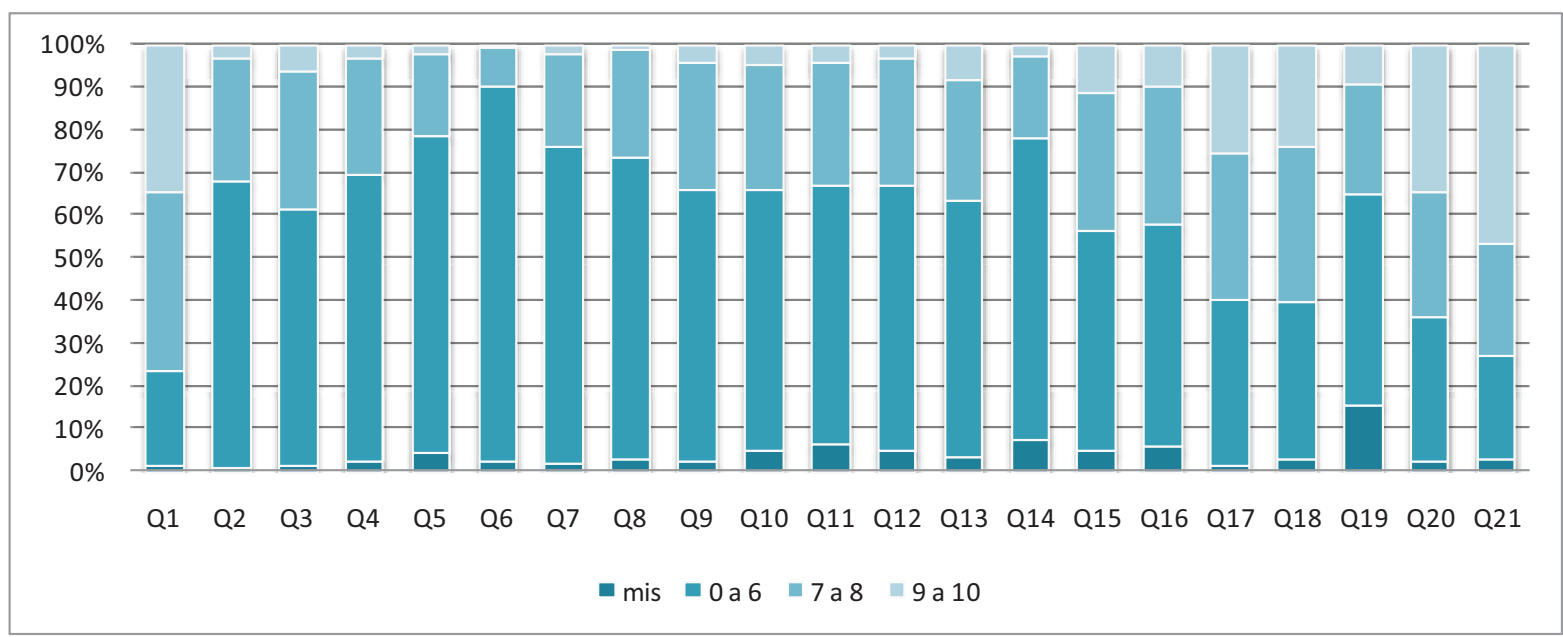

Gráfico 3.3.2.1 - Proporção de respondentes por questão no cluster alunos insatisfeitos

Sendo:

Q1 - Domínio do conteúdo ministrado

Q2 - Qualidade na transmissão do conteúdo

Q3 - Entusiasmo demonstrado na transmissão do conteúdo

Q4 - Incentivo à participação dos alunos nas atividades previstas no programa da disciplina

Q5 - Incentivo, ao aluno, à realização de atividades adicionais de aprofundamento do aprendizado

Q6 - Uso de estratégias para motivar os alunos em relação ao conteúdo

Q7 - Ritmo de apresentação do conteúdo

Q8 - Adequação das atividades desenvolvidas para o alcance dos objetivos propostos

Q9 - Profundidade com que o conteúdo foi abordado, considerando os objetivos da disciplina

Q10 - Integração do conteúdo da disciplina com conteúdos conexos de outras disciplinas

Q11 - Integração entre teoria, pesquisa e/ou aspectos da realidade

Q12 - Qualidade dos exemplos utilizados para relacionar teoria, pesquisa e prática

Q13 - Coerência entre nível de complexidade das avaliações (trabalhos, testes,

provas, exercícios, etc) e o conteúdo ministrado 
Q14 - Discussão dos resultados de avaliações de aprendizagem

Q15 - Adequação do uso dos recursos de ensino (quadro de giz, retroprojetor, etc)

Q16 - Disponibilidade para esclarecer dúvidas e solucionar dificuldades dos alunos,

relacionadas ao conteúdo da disciplina

Q17 - Cordialidade na relação com os alunos

Q18 - Respeito às idéias manifestadas pelos alunos acerca dos temas abordados

Q19 - Disponibilidade para atendimento extraclasse

Q20 - Cumprimento dos horários de início e término das aulas, pelo professor

Q21 - Assiduidade

A partir do gráfico 3.3.2.1, é possível indicar o atributo que está sendo menos bem avaliados pelos alunos. A seguir:

* Uso de estratégias para motivar os alunos em relação ao conteúdo.

Esse item é mais difícil de obter algum grau de satisfação dos alunos, pois, em geral, o percentual de notas de 0 a 6 , corresponde a $90 \%$ das respostas.

Da mesma forma, o item mais fácil de obter alguma satisfação dos alunos, cerca de $75 \%$ de notas maiores que 6 , deste cluster são:

$\checkmark$ Assiduidade

$\checkmark$ Domínio do conteúdo ministrado

Os atributos destacados como pontos fortes e a melhorar neste cluster são os mesmo do cluster dos alunos muito insatisfeitos.

\subsubsection{Cluster Satisfeito}

O cluster dos alunos satisfeitos com seus docentes corresponde aos julgamentos com notas 7 a10. Esse cluster é o mais significativo, pois, representa a maior parte dos alunos que responderam o questionário, nos períodos estudados, cerca de $48 \%$.

A seguir Gráfico 3.3.3.1 com a proporção de respostas para cada item avaliado no cluster em estudo. 


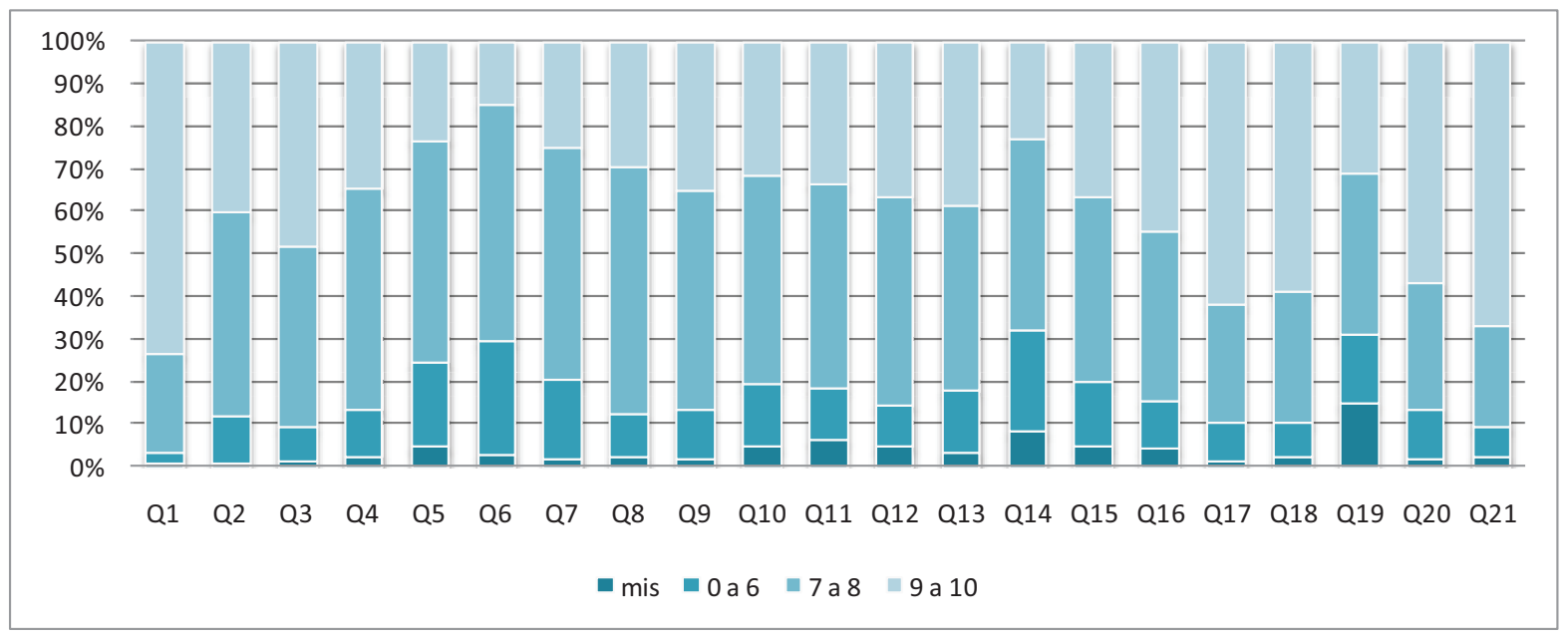

Gráfico 3.3.3.1 - Proporção de respondentes por questão no cluster alunos satisfeitos

Sendo:

Q1 - Domínio do conteúdo ministrado

Q2 - Qualidade na transmissão do conteúdo

Q3 - Entusiasmo demonstrado na transmissão do conteúdo

Q4 - Incentivo à participação dos alunos nas atividades previstas no programa da disciplina

Q5 - Incentivo, ao aluno, à realização de atividades adicionais de aprofundamento do aprendizado

Q6 - Uso de estratégias para motivar os alunos em relação ao conteúdo

Q7 - Ritmo de apresentação do conteúdo

Q8 - Adequação das atividades desenvolvidas para o alcance dos objetivos propostos

Q9 - Profundidade com que o conteúdo foi abordado, considerando os objetivos da disciplina

Q10 - Integração do conteúdo da disciplina com conteúdos conexos de outras

disciplinas

Q11 - Integração entre teoria, pesquisa e/ou aspectos da realidade

Q12 - Qualidade dos exemplos utilizados para relacionar teoria, pesquisa e prática

Q13 - Coerência entre nível de complexidade das avaliações (trabalhos, testes, provas, exercícios, etc) e o conteúdo ministrado

Q14 - Discussão dos resultados de avaliações de aprendizagem

Q15 - Adequação do uso dos recursos de ensino (quadro de giz, retroprojetor, etc)

Q16 - Disponibilidade para esclarecer dúvidas e solucionar dificuldades dos alunos, relacionadas ao conteúdo da disciplina

Q17 - Cordialidade na relação com os alunos

Q18 - Respeito às idéias manifestadas pelos alunos acerca dos temas abordados

Q19 - Disponibilidade para atendimento extraclasse

Q20 - Cumprimento dos horários de início e término das aulas, pelo professor

Q21 - Assiduidade 
Entre todas as 21 questões, destacam questões que podem ser consideradas mais difíceis de obter satisfação dos alunos e as mais fáceis.

Assim, questões com percentual em torno de $90 \%$ das notas de 7 a 10 são consideradas mais fáceis de obter satisfação. São elas:

$\checkmark$ Domínio do conteúdo ministrado;

$\checkmark$ Assiduidade.

E questões que possuem o menor percentual de notas de 7 a 10 são mais difíceis de obter satisfação. São elas:

* Incentivo, ao aluno, à realização de atividades adicionais de aprofundamento do aprendizado;

* Discussão dos resultados de avaliações de aprendizagem;

* Uso de estratégias para motivar os alunos em relação ao conteúdo.

Este cluster obteve os mesmos atributos destacados como pontos fortes e a melhorar em relação as análises gerais e cluster já apresentados.

\subsubsection{Cluster Muito Satisfeito}

O cluster dos alunos muito satisfeitos é representado pelos julgamentos em sua grande maioria 9 e 10 aos 21 itens apresentados. Ele representa o segundo maior cluster desse estudo.

Este cluster apresenta o mesmo comportamento em relação ao levantamento de pontos forte e a melhorar das análises gerais e por cluster. Esse comportamento pode ser observado no gráfico a seguir.

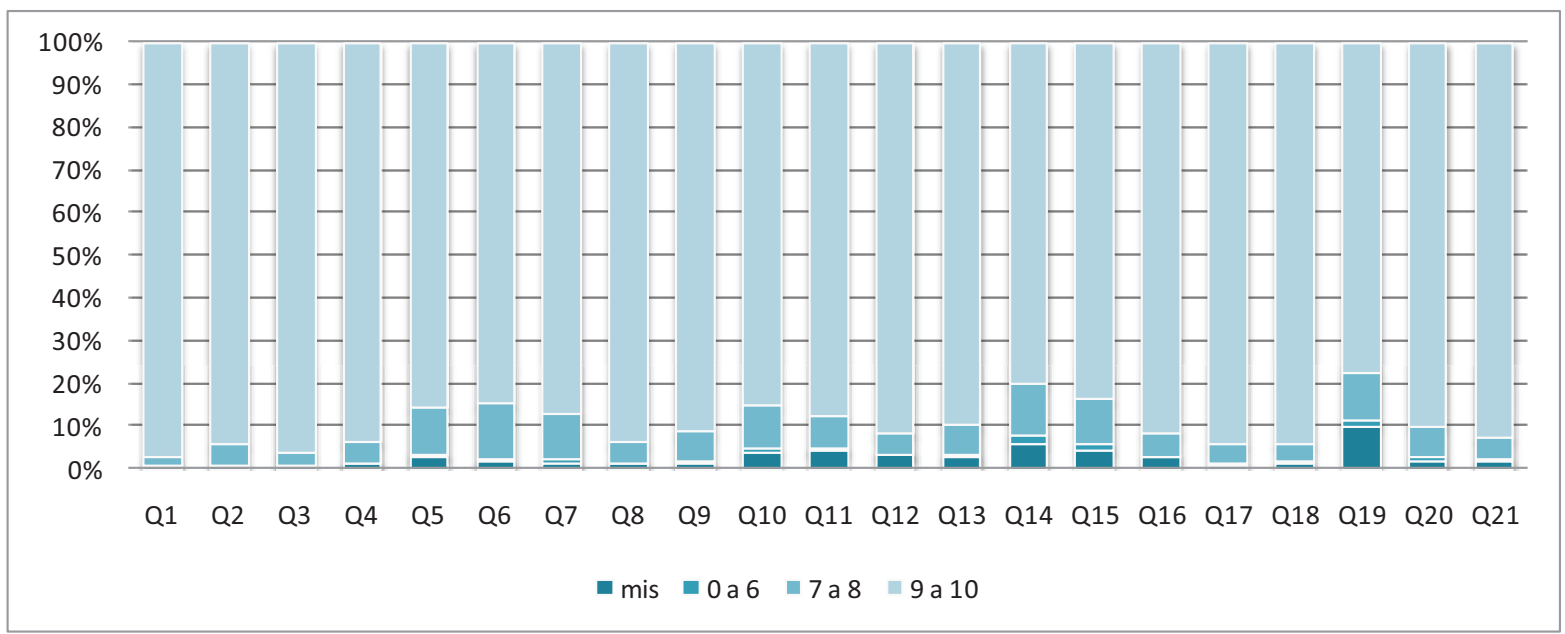


Gráfico 3.3.4.1 - Proporção de respondentes por questão no cluster alunos muito satisfeitos

Sendo:

Q1 - Domínio do conteúdo ministrado

Q2 - Qualidade na transmissão do conteúdo

Q3 - Entusiasmo demonstrado na transmissão do conteúdo

Q4 - Incentivo à participação dos alunos nas atividades previstas no programa da disciplina

Q5 - Incentivo, ao aluno, à realização de atividades adicionais de aprofundamento do aprendizado

Q6 - Uso de estratégias para motivar os alunos em relação ao conteúdo

Q7 - Ritmo de apresentação do conteúdo

Q8 - Adequação das atividades desenvolvidas para o alcance dos objetivos propostos

Q9 - Profundidade com que o conteúdo foi abordado, considerando os objetivos da disciplina

Q10 - Integração do conteúdo da disciplina com conteúdos conexos de outras disciplinas

Q11 - Integração entre teoria, pesquisa e/ou aspectos da realidade

Q12 - Qualidade dos exemplos utilizados para relacionar teoria, pesquisa e prática

Q13 - Coerência entre nível de complexidade das avaliações (trabalhos, testes, provas, exercícios, etc) e o conteúdo ministrado

Q14 - Discussão dos resultados de avaliações de aprendizagem

Q15 - Adequação do uso dos recursos de ensino (quadro de giz, retroprojetor, etc)

Q16 - Disponibilidade para esclarecer dúvidas e solucionar dificuldades dos alunos, relacionadas ao conteúdo da disciplina

Q17 - Cordialidade na relação com os alunos

Q18 - Respeito às idéias manifestadas pelos alunos acerca dos temas abordados

Q19 - Disponibilidade para atendimento extraclasse

Q20 - Cumprimento dos horários de início e término das aulas, pelo professor

Q21 - Assiduidade 


\section{CONCLUSÕES}

O estudo demonstrou a relevância do cálculo de medidas de satisfação pela técnica TRI e ajuste do método no banco de dados para a realização de análises de índices de satisfação.

Foi possível ampliar a interpretação acerca dos níveis de satisfação dos estudantes que responderam ao questionário em relação ao desempenho de seus professores e conhecer melhor o processo de avaliação.

Os dados analisados indicaram que na Universidade, há alunos que estão muito insatisfeitos com seus docentes até alunos muito satisfeitos. O grupo dos alunos muito satisfeitos juntamente com o dos alunos satisfeitos representa a maior parte dos alunos da UnB.

Conclui-se então que as alterações na Universidade no que se refere à estrutura e relações de trabalho parecem ainda não ter influenciado de forma direta a satisfação dos alunos, que responderam ao questionário, em relação ao desempenho dos docentes na UnB, já que o nível de satisfação destes é alta e constante no decorrer do tempo.

Sobretudo é possível apontar pontos fortes e a melhorar em relação à satisfação dos alunos quanto ao desempenho dos docentes. Observa-se que os pontos a melhorar estão relacionados principalmente às práticas pedagógicas no que se refere ao uso de estratégias para motivar os alunos em relação ao conteúdo e discussão dos resultados de avaliações de aprendizagem. Já os pontos fortes estão relacionados com a relação dos professores com os alunos, como cordialidade na relação com os alunos e respeito às idéias manifestadas pelos alunos acerca dos temas abordados.

Espera-se que esse trabalho seja tratado como um meio de aperfeiçoar o trabalho pedagógico dos docentes e que ressalte a necessidade de capacitação constante no que se refere a práticas pedagógicas. Além disso, ressaltar a necessidade de que a avaliação discente dever ser sustentada por uma cultura de aprendizado deixando de ser puramente um processo institucionalizado e burocrático.

Por fim, é necessário ressaltar que esse trabalho possui limitações dentro das quais precisa ser compreendido. Uma delas é a constatação de que a avaliação na 
UnB necessita aprimorar o processo avaliativo no que se refere ao seu instrumento, logística de aplicação e período de aplicação possibilitando assim uma análise mais precisa da satisfação dos alunos em relação aos seus docentes. 


\section{REFERÊNCIAS}

Abrantes, P., Valente, M. O. et AL. (no prelo).Estudo sobre a avaliação dos docentes do ensino superior; Desenvolvimento de instrumentos de avaliação de desempenho - Relatório final. Lisboa. Direção Geral do Ensino Superior. Disponível em:

http://www.educ.fc.ul.pt/docentes/msantos/textos/eensinosuperior.pdf>,

Acesso $17 / 07 / 2010$.

Andrade,D. F. de; Tavares, H. R.; Valle, R. da C., Teoria de Resposta ao Item:conceitos e aplicações., São Paulo: ABE - Associação Brasileira de Estatística,SINAPE, 2000.

Chauí, Marilena, Sociedade, Universidade e Estado: autonomia, dependência e compromisso social. Seminário: Universidade: Por que e como reformar? MEC/SESu: agosto, 2003.

COELHO JUNIOR, F. A. Suporte a Aprendizagem, Satisfação no Trabalho e Desempenho: Um Estudo Multinível. Tese de Doutorado. Brasília: Universidade de Brasília, 2009.

Ferreira, M. C. C. Erro! A referência de hiperlink não é válida. publicado 3/03/2010 Disponível em: < http://www.webartigos.com>, Acesso 30/06/2010.

Garcia, R. C. Subsídios para Organizar Avaliações da Ação Governamental. Texto para discussão N. 776. Brasília: Instituto de Pesquisas Econômicas Aplicadas, 2001.

Libâneo, J. C. Pedagogia e pedagogos, para quê? São Paulo: Cortez, 2007.

Masetto, Marcos. Docência Na Universidade. São Paulo, Papirus. 1998

Morettin, P.A.; Bussab, W.O., Estatística básica, São Paulo: Saraiva. 5.ed., 2004. $526 p$.

Odelius, C. C; Santos, P. R. G., 10 Avaliação de desempenho individual na administração pública federal: aspectos intervenientes no processo e nos resultados, Revista Economia \& Gestão da PUC Minas, publicado junho/2007, Disponível em:

http://periodicos.pucminas.br/index.php/economiaegestao/article/view/7/13>.

Pantoja, M. J. Avaliação de Impacto de Treinamento no Trabalho na àrea de Reabilitação: preditores individuais e situacionais. Dissertação de Mestrado. Brasília: Universidade de Brasília, 1999. 
Pestana, M. I. Avaliação Educacional - O sistema nacional de avaliação da educação básica. Editora Cortez. Instituto de Estudos Especiais. Pontifica Universidade Católica de São Paulo, 1988.

REUNI, Formulário de Apresentação de Proposta. julho, 2008.

Rossi, CAV; Slongo LA. Pesquisa de satisfação de clientes: 0 Estado-da-arte e proposição de um método brasileiro. RAC, v.2, n.1, p.101-25, 1998.

Silva, C. S. Medidas e Avaliação em Educação. Petrópolis: Ed. Vozes, 1992.

Soares, T. M. (2005) Utilização da teoria da resposta ao item na produção de indicadores socioeconômicos. Pesquisa Operacional, 25, 83-112.

Souza, E. C. O. Criando textos segundo ABNT em Word. Disponível em: < http://www.scribd.com/doc/1816529/Normas-ABNT-no-Word>. Acesso em 07 junho. 2010.

Tonello, D. M. M. Avaliação formativa: o que observar, o que avaliar, para que avaliar? Projeto Pitanguá. Março, 2010. Disponível em: < http://www.moderna.com.br/moderna/projetopitangua/docs/orientacoes_avaliacao_fo rmativa.pdf > Acesso em 1 julho de 2010.

VASCONCELOS. Maria Lucia. Docência e Autoridade no Ensino Superior: Uma Introdução ao Debate. Ensinar e Aprender no Ensino Superior. 2.ed. São Paulo: Cortez. 2005. 


\section{APÊNDICE}

\section{Apêndice A - tabelas cluster muito insatisfeito}

Domínio do conteúdo ministrado

\begin{tabular}{|c|c|c|c|c|c|}
\hline Ano_Semestre & \multicolumn{4}{|c|}{ Nota } & Total \\
\hline "2003_01 & $66 \%$ & $24 \%$ & 9\% & $1 \%$ & $100 \%$ \\
\hline 2006_02 & $71 \%$ & $21 \%$ & $6 \%$ & $2 \%$ & $100 \%$ \\
\hline 2007_02 & $72 \%$ & $21 \%$ & $6 \%$ & $1 \%$ & $100 \%$ \\
\hline 2008_01 & $71 \%$ & $22 \%$ & $6 \%$ & $1 \%$ & $100 \%$ \\
\hline 2008_02 & $70 \%$ & $22 \%$ & $7 \%$ & $1 \%$ & $100 \%$ \\
\hline 2009_01 & $73 \%$ & $19 \%$ & $6 \%$ & $2 \%$ & $100 \%$ \\
\hline Total & $70 \%$ & $21 \%$ & $7 \%$ & $2 \%$ & $100 \%$ \\
\hline
\end{tabular}

Qualidade na transmissão do conteúdo

\begin{tabular}{|c|c|c|c|c|c|}
\hline Ano_Semestre & \multicolumn{5}{|c|}{ Nota } \\
\hline 2003_01 & $96 \%$ & $3 \%$ & "0\% & $1 \%$ & $100 \%$ \\
\hline 2006_02 & $96 \%$ & $3 \%$ & $0 \%$ & $1 \%$ & $100 \%$ \\
\hline 2007_02 & $97 \%$ & $2 \%$ & $0 \%$ & $1 \%$ & $100 \%$ \\
\hline 2008_01 & $96 \%$ & $3 \%$ & $0 \%$ & $1 \%$ & $100 \%$ \\
\hline 2008_02 & $96 \%$ & $2 \%$ & $0 \%$ & $1 \%$ & $100 \%$ \\
\hline 2009_01 & $96 \%$ & $2 \%$ & $0 \%$ & $1 \%$ & $100 \%$ \\
\hline Total & $96 \%$ & $3 \%$ & $0 \%$ & $1 \%$ & $100 \%$ \\
\hline
\end{tabular}

Entusiasmo demonstrado na transmissão do conteúdo

\begin{tabular}{|c|c|c|c|c|c|}
\hline Ano_Semestre & 0 a 6 & 7 a 8 & $\begin{array}{l}\text { Nota } \\
9 \text { a } 10\end{array}$ & $\mathrm{~m}$ is & Total \\
\hline 2003_01 & $94 \%$ & $4 \%$ & "0\% & $1 \%$ & $100 \%$ \\
\hline 2006_02 & $95 \%$ & $3 \%$ & $1 \%$ & $1 \%$ & $100 \%$ \\
\hline 2007_02 & $95 \%$ & $3 \%$ & $1 \%$ & $1 \%$ & $100 \%$ \\
\hline 2008_01 & $94 \%$ & $5 \%$ & $1 \%$ & $1 \%$ & $100 \%$ \\
\hline 2008_02 & $94 \%$ & $4 \%$ & $0 \%$ & $1 \%$ & $100 \%$ \\
\hline 2009_01 & $95 \%$ & $3 \%$ & $0 \%$ & $1 \%$ & $100 \%$ \\
\hline Total & $95 \%$ & $4 \%$ & $0 \%$ & $1 \%$ & $100 \%$ \\
\hline
\end{tabular}

Incentivo à participação dos alunos nas atividades previstas no programa da disciplina

\begin{tabular}{|c|c|c|c|c|c|c|}
\hline \multicolumn{2}{|l|}{ Ano_Semestre } & 0 a 6 & 7 a 8 & $\begin{array}{c}\text { Nota } \\
9 \text { a } 10\end{array}$ & $\mathrm{~m}$ is & Total \\
\hline & 2003_01 & $96 \%$ & $3 \%$ & $0 \%$ & $2 \%$ & $100 \%$ \\
\hline & 2006_02 & $94 \%$ & $2 \%$ & $0 \%$ & $3 \%$ & $100 \%$ \\
\hline & 2007_02 & $96 \%$ & $2 \%$ & $0 \%$ & $2 \%$ & $100 \%$ \\
\hline & 2008_01 & $95 \%$ & $3 \%$ & $0 \%$ & $1 \%$ & $100 \%$ \\
\hline & 2008_02 & $96 \%$ & $2 \%$ & $0 \%$ & $2 \%$ & $100 \%$ \\
\hline & 2009_01 & $95 \%$ & $3 \%$ & $0 \%$ & $2 \%$ & $100 \%$ \\
\hline & Total & $95 \%$ & $2 \%$ & $0 \%$ & $2 \%$ & $100 \%$ \\
\hline
\end{tabular}

Incentivo, ao aluno, à realização de atividades adicionais de aprofundamento do aprendizado 


\begin{tabular}{|c|c|c|c|c|c|}
\hline Ano_Semestre & 0 a 6 & 7 a 8 & $\begin{array}{c}\text { Nota } \\
9 \text { a } 10\end{array}$ & $\mathrm{~m}$ is & Total \\
\hline 2003_01 & $96 \%$ & $2 \%$ & $0 \%$ & $2 \%$ & $100 \%$ \\
\hline 2006_02 & $93 \%$ & $2 \%$ & $0 \%$ & $5 \%$ & $100 \%$ \\
\hline 2007_02 & $95 \%$ & $2 \%$ & $0 \%$ & $3 \%$ & $100 \%$ \\
\hline 2008_01 & $96 \%$ & $2 \%$ & $0 \%$ & $2 \%$ & $100 \%$ \\
\hline 2008_02 & $95 \%$ & $2 \%$ & $0 \%$ & $3 \%$ & $100 \%$ \\
\hline 2009_01 & $95 \%$ & $2 \%$ & $0 \%$ & $4 \%$ & $100 \%$ \\
\hline Total & $95 \%$ & $2 \%$ & $0 \%$ & $3 \%$ & $100 \%$ \\
\hline
\end{tabular}

Uso de estratégias para motivar os alunos em relação ao conteúdo

\begin{tabular}{|c|c|c|c|c|c|}
\hline Ano_Semestre & 0 a 6 & 7 a 8 & $\begin{array}{c}\text { Nota } \\
9 \text { a } 10\end{array}$ & $\mathrm{~m}$ is & Total \\
\hline 2003_01 & $98 \%$ & $1 \%$ & $0 \%$ & $2 \%$ & $100 \%$ \\
\hline 2006_02 & $97 \%$ & $0 \%$ & $0 \%$ & $3 \%$ & $100 \%$ \\
\hline 2007_02 & $98 \%$ & $1 \%$ & $0 \%$ & $2 \%$ & $100 \%$ \\
\hline 2008_01 & $98 \%$ & $1 \%$ & $0 \%$ & $1 \%$ & $100 \%$ \\
\hline 2008_02 & $98 \%$ & $1 \%$ & $0 \%$ & $1 \%$ & $100 \%$ \\
\hline 2009_01 & $97 \%$ & $1 \%$ & $0 \%$ & $2 \%$ & $100 \%$ \\
\hline Total & $98 \%$ & $1 \%$ & $0 \%$ & $2 \%$ & $100 \%$ \\
\hline
\end{tabular}

Ritmo de apresentação do conteúdo

\begin{tabular}{|c|c|c|c|c|c|}
\hline Ano_Semestre & \multicolumn{4}{|c|}{ Nota } & Total \\
\hline "2003_01 & $96 \%$ & $2 \%$ & "0\% & $2 \%$ & $100 \%$ \\
\hline 2006_02 & $95 \%$ & $2 \%$ & $0 \%$ & $3 \%$ & $100 \%$ \\
\hline 2007_02 & $96 \%$ & $2 \%$ & $0 \%$ & $2 \%$ & $100 \%$ \\
\hline 2008_01 & $97 \%$ & $2 \%$ & $0 \%$ & $1 \%$ & $100 \%$ \\
\hline 2008_02 & $96 \%$ & $2 \%$ & $0 \%$ & $1 \%$ & $100 \%$ \\
\hline 2009_01 & $94 \%$ & $3 \%$ & $0 \%$ & $3 \%$ & $100 \%$ \\
\hline Total & $96 \%$ & $2 \%$ & $0 \%$ & $2 \%$ & $100 \%$ \\
\hline
\end{tabular}

Adequação das atividades desenvolvidas para o alcance dos objetivos propostos

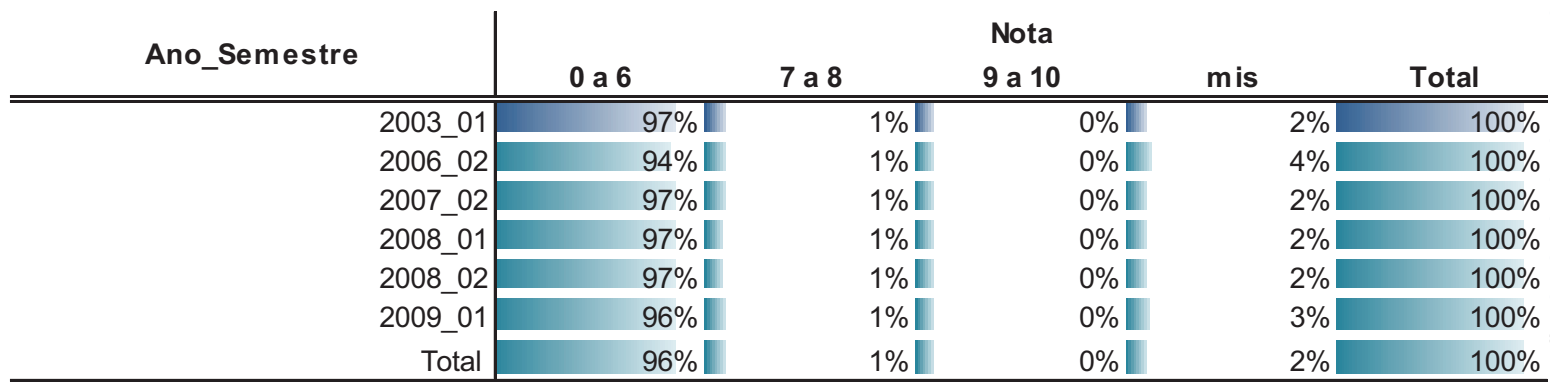

Profundidade com que o conteúdo foi abordado, considerando os objetivos da disciplina

\begin{tabular}{|c|c|c|c|c|c|}
\hline Ano_Semestre & 0 a 6 & \multicolumn{3}{|c|}{ Nota } & Total \\
\hline "2003_01 & $96 \%$ & $2 \%$ & $0 \%$ & $2 \%$ & $100 \%$ \\
\hline 2006_02 & $94 \%$ & $2 \%$ & $0 \%$ & $3 \%$ & $100 \%$ \\
\hline 2007_02 & $95 \%$ & $3 \%$ & $0 \%$ & $2 \%$ & $100 \%$ \\
\hline 2008_01 & $96 \%$ & $2 \%$ & $0 \%$ & $2 \%$ & $100 \%$ \\
\hline 2008_02 & $95 \%$ & $3 \%$ & $0 \%$ & $2 \%$ & $100 \%$ \\
\hline 2009_01 & $94 \%$ & $3 \%$ & $0 \%$ & $3 \%$ & $100 \%$ \\
\hline Total & $95 \%$ & $2 \%$ & $0 \%$ & $2 \%$ & $100 \%$ \\
\hline
\end{tabular}

Integração do conteúdo da disciplina com conteúdos conexos de outras disciplinas 


\begin{tabular}{|c|c|c|c|c|c|}
\hline Ano_Semestre & \multicolumn{4}{|c|}{ Nota } & Total \\
\hline 2003_01 & $93 \%$ & $4 \%$ & $0 \%$ & $3 \%$ & $100 \%$ \\
\hline 2006_02 & $90 \%$ & $4 \%$ & $0 \%$ & $6 \%$ & $100 \%$ \\
\hline 2007_02 & $91 \%$ & $4 \%$ & $0 \%$ & $4 \%$ & $100 \%$ \\
\hline 2008_01 & $93 \%$ & $4 \%$ & $0 \%$ & $2 \%$ & $100 \%$ \\
\hline 2008_02 & $92 \%$ & $4 \%$ & $0 \%$ & $4 \%$ & $100 \%$ \\
\hline 2009_01 & $92 \%$ & $4 \%$ & $0 \%$ & $5 \%$ & $100 \%$ \\
\hline Total & $92 \%$ & $4 \%$ & $0 \%$ & $4 \%$ & $100 \%$ \\
\hline
\end{tabular}

Integração entre teoria, pesquisa e/ou aspectos da realidade

\begin{tabular}{|c|c|c|c|c|c|}
\hline Ano_Semestre & 0 a 6 & 7 a 8 & $\begin{array}{c}\text { Nota } \\
9 \text { a } 10\end{array}$ & $\mathrm{~m}$ is & Total \\
\hline 2003_01 & $92 \%$ & "3\% & $0 \%$ & $5 \%$ & $100 \%$ \\
\hline 2006_02 & $89 \%$ & $2 \%$ & $0 \%$ & $8 \%$ & $100 \%$ \\
\hline 2007_02 & $92 \%$ & $3 \%$ & $0 \%$ & $5 \%$ & $100 \%$ \\
\hline 2008_01 & $93 \%$ & $3 \%$ & $0 \%$ & $3 \%$ & $100 \%$ \\
\hline 2008_02 & $93 \%$ & $2 \%$ & $0 \%$ & $5 \%$ & $100 \%$ \\
\hline 2009_01 & $91 \%$ & $3 \%$ & $0 \%$ & $5 \%$ & $100 \%$ \\
\hline Total & $92 \%$ & $3 \%$ & $0 \%$ & $5 \%$ & $100 \%$ \\
\hline
\end{tabular}

Qualidade dos exemplos utilizados para relacionar teoria, pesquisa e prática

\begin{tabular}{|c|c|c|c|c|c|}
\hline Ano_Semestre & \multicolumn{5}{|c|}{ Nota } \\
\hline 2003_01 & $94 \%$ & $2 \%$ & ("0\% & "4\% & $100 \%$ \\
\hline 2006_02 & $94 \%$ & $2 \%$ & $0 \%$ & $4 \%$ & $100 \%$ \\
\hline 2007_02 & $95 \%$ & $1 \%$ & $0 \%$ & $4 \%$ & $100 \%$ \\
\hline 2008_01 & $96 \%$ & $2 \%$ & $0 \%$ & $2 \%$ & $100 \%$ \\
\hline 2008_02 & $95 \%$ & $2 \%$ & $0 \%$ & $3 \%$ & $100 \%$ \\
\hline 2009_01 & $93 \%$ & $2 \%$ & $0 \%$ & $5 \%$ & $100 \%$ \\
\hline Total & $94 \%$ & $2 \%$ & $0 \%$ & $4 \%$ & $100 \%$ \\
\hline
\end{tabular}

Coerência entre nível de complexidade das avaliações e o conteúdo ministrado

\begin{tabular}{|c|c|c|c|c|c|c|}
\hline \multicolumn{2}{|l|}{ Ano_Semestre } & 0 a 6 & \multicolumn{2}{|r|}{ Nota } & $\mathrm{m}$ is & Total \\
\hline & 2003_01 & $90 \%$ & "5\% & $1 \%$ & $4 \%$ & $100 \%$ \\
\hline & 2006_02 & $91 \%$ & $5 \%$ & $1 \%$ & $3 \%$ & $100 \%$ \\
\hline & 2007_02 & $91 \%$ & $6 \%$ & $1 \%$ & $2 \%$ & $100 \%$ \\
\hline & 2008_01 & $92 \%$ & $5 \%$ & $1 \%$ & $3 \%$ & $100 \%$ \\
\hline & 2008_02 & $92 \%$ & $5 \%$ & $1 \%$ & $3 \%$ & $100 \%$ \\
\hline & 2009_01 & $90 \%$ & $5 \%$ & $0 \%$ & $4 \%$ & $100 \%$ \\
\hline & Total & $91 \%$ & $5 \%$ & $1 \%$ & $3 \%$ & $100 \%$ \\
\hline
\end{tabular}

Discussão dos resultados de avaliações de aprendizagem

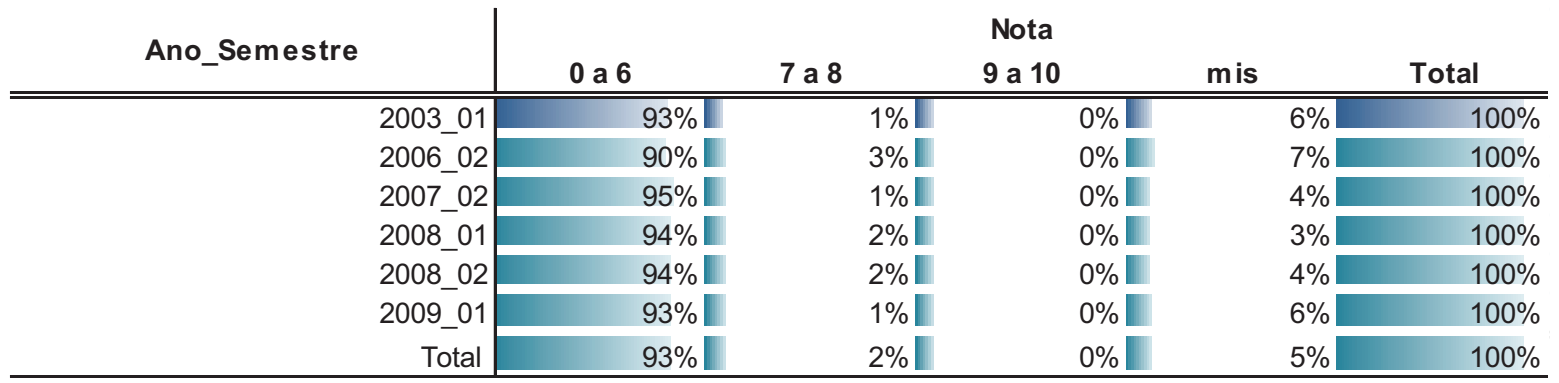

Adequação do uso dos recursos de ensino 


\begin{tabular}{|c|c|c|c|c|c|}
\hline Ano_Semestre & \multicolumn{5}{|c|}{ Nota } \\
\hline "2003_01 & $86 \%$ & $7 \%$ & 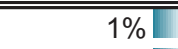 & "6\% & $100 \%$ \\
\hline 2006_02 & $84 \%$ & $8 \%$ & $2 \%$ & $6 \%$ & $100 \%$ \\
\hline 2007_02 & $86 \%$ & $9 \%$ & $2 \%$ & $3 \%$ & $100 \%$ \\
\hline 2008_01 & $86 \%$ & $8 \%$ & $1 \%$ & $4 \%$ & $100 \%$ \\
\hline 2008_02 & $83 \%$ & $11 \%$ & $1 \%$ & $5 \%$ & $100 \%$ \\
\hline 2009_01 & $85 \%$ & $9 \%$ & $2 \%$ & $5 \%$ & $100 \%$ \\
\hline Total & $85 \%$ & $9 \%$ & $1 \%$ & $5 \%$ & $100 \%$ \\
\hline
\end{tabular}

Disponibilidade para esclarecer dúvidas e solucionar dificuldades dos alunos, relacionadas ao conteúdo da disciplina

\begin{tabular}{|c|c|c|c|c|c|}
\hline Ano_Semestre & \multicolumn{5}{|c|}{ Nota } \\
\hline 2003_01 & $92 \%$ & $4 \%$ & $0 \%$ & $4 \%$ & $100 \%$ \\
\hline 2006_02 & $89 \%$ & $5 \%$ & $0 \%$ & $6 \%$ & $100 \%$ \\
\hline 2007_02 & $91 \%$ & $4 \%$ & $0 \%$ & $5 \%$ & $100 \%$ \\
\hline 2008_01 & $90 \%$ & $6 \%$ & $0 \%$ & $4 \%$ & $100 \%$ \\
\hline 2008_02 & $91 \%$ & $5 \%$ & $0 \%$ & $4 \%$ & $100 \%$ \\
\hline 2009_01 & $90 \%$ & $5 \%$ & $0 \%$ & $5 \%$ & $100 \%$ \\
\hline Total & $91 \%$ & $5 \%$ & $0 \%$ & $4 \%$ & $100 \%$ \\
\hline
\end{tabular}

Cordialidade na relação com os alunos

\begin{tabular}{|c|c|c|c|c|c|}
\hline Ano_Semestre & \multicolumn{5}{|c|}{ Nota } \\
\hline 2003_01 & $81 \%$ & $15 \%$ & $3 \%$ & $2 \%$ & $100 \%$ \\
\hline 2006_02 & $80 \%$ & $14 \%$ & $3 \%$ & $3 \%$ & $100 \%$ \\
\hline 2007_02 & $83 \%$ & $13 \%$ & $2 \%$ & $2 \%$ & $100 \%$ \\
\hline 2008_01 & $79 \%$ & $15 \%$ & $3 \%$ & $3 \%$ & $100 \%$ \\
\hline 2008_02 & $81 \%$ & $15 \%$ & $3 \%$ & $2 \%$ & $100 \%$ \\
\hline 2009_01 & $81 \%$ & $14 \%$ & $3 \%$ & $2 \%$ & $100 \%$ \\
\hline Total & $81 \%$ & $14 \%$ & $3 \%$ & $2 \%$ & $100 \%$ \\
\hline
\end{tabular}

Respeito às idéias manifestadas pelos alunos acerca dos temas abordados

\begin{tabular}{|c|c|c|c|c|c|c|}
\hline \multicolumn{2}{|l|}{ Ano_Semestre } & \multicolumn{5}{|c|}{ Nota } \\
\hline & "2003_01 & $81 \%$ & 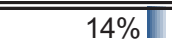 & $2 \%$ & "4\% & $100 \%$ \\
\hline & 2006_02 & $80 \%$ & $14 \%$ & $2 \%$ & $3 \%$ & $100 \%$ \\
\hline & 2007_02 & $82 \%$ & $13 \%$ & $2 \%$ & $3 \%$ & $100 \%$ \\
\hline & 2008_01 & $81 \%$ & $14 \%$ & $2 \%$ & $3 \%$ & $100 \%$ \\
\hline & 2008_02 & $80 \%$ & $15 \%$ & $2 \%$ & $3 \%$ & $100 \%$ \\
\hline & 2009_01 & $80 \%$ & $15 \%$ & $2 \%$ & $3 \%$ & $100 \%$ \\
\hline & Total & $81 \%$ & $14 \%$ & $2 \%$ & $3 \%$ & $100 \%$ \\
\hline
\end{tabular}

Disponibilidade para atendimento extra-classe

\begin{tabular}{|c|c|c|c|c|c|}
\hline Ano_Semestre & \multicolumn{4}{|c|}{ Nota } & Total \\
\hline "2003_01 & $87 \%$ & "5\% & $0 \%$ & $8 \%$ & $100 \%$ \\
\hline 2006_02 & $79 \%$ & $6 \%$ & $1 \%$ & $15 \%$ & $100 \%$ \\
\hline 2007_02 & $82 \%$ & $6 \%$ & $0 \%$ & $12 \%$ & $100 \%$ \\
\hline 2008_01 & $82 \%$ & $7 \%$ & $1 \%$ & $10 \%$ & $100 \%$ \\
\hline 2008_02 & $84 \%$ & $6 \%$ & $1 \%$ & $10 \%$ & $100 \%$ \\
\hline 2009_01 & $85 \%$ & $5 \%$ & $0 \%$ & $10 \%$ & $100 \%$ \\
\hline Total & $84 \%$ & $6 \%$ & $0 \%$ & $10 \%$ & $100 \%$ \\
\hline
\end{tabular}

Cumprimento dos horários de início e término das aulas, pelo professor 


\begin{tabular}{|c|c|c|c|c|c|}
\hline \multirow{2}{*}{ Ano_Semestre } & \multicolumn{5}{|c|}{ Nota } \\
\hline & 0 a 6 & 7 a 8 & 9 a 10 & $\mathrm{~m}$ is & Total \\
\hline "2003_01 & $70 \%$ & 18\% & $10 \%$ & $3 \%$ & $100 \%$ \\
\hline 2006_02 & $71 \%$ & $14 \%$ & $12 \%$ & $3 \%$ & $100 \%$ \\
\hline 2007_02 & $70 \%$ & $18 \%$ & $9 \%$ & $2 \%$ & $100 \%$ \\
\hline 2008_01 & $73 \%$ & $15 \%$ & $9 \%$ & $3 \%$ & $100 \%$ \\
\hline 2008_02 & $71 \%$ & $17 \%$ & $9 \%$ & $2 \%$ & $100 \%$ \\
\hline 2009_01 & $73 \%$ & $16 \%$ & $9 \%$ & $3 \%$ & $100 \%$ \\
\hline Total & $71 \%$ & $17 \%$ & $10 \%$ & $3 \%$ & $100 \%$ \\
\hline
\end{tabular}

Assiduidade

\begin{tabular}{|c|c|c|c|c|c|c|}
\hline Ano_Semestre & \multicolumn{6}{|c|}{ Nota } \\
\hline 2003_01 & & $57 \%$ & $19 \%$ & $22 \%$ & $3 \%$ & $100 \%$ \\
\hline 2006_02 & & $58 \%$ & $19 \%$ & $18 \%$ & $4 \%$ & $100 \%$ \\
\hline 2007_02 & & $59 \%$ & $20 \%$ & $19 \%$ & $2 \%$ & $100 \%$ \\
\hline 2008_01 & & $63 \%$ & $17 \%$ & $17 \%$ & $3 \%$ & $100 \%$ \\
\hline 2008_02 & & $61 \%$ & $19 \%$ & $18 \%$ & $2 \%$ & $100 \%$ \\
\hline 2009_01 & & $61 \%$ & $19 \%$ & $17 \%$ & $4 \%$ & $100 \%$ \\
\hline Total & & $59 \%$ & $19 \%$ & $19 \%$ & $3 \%$ & $100 \%$ \\
\hline
\end{tabular}

\section{Apêndice $B$ - tabelas cluster insatisfeito}

Domínio do conteúdo ministrado

\begin{tabular}{|c|c|c|c|c|c|}
\hline Ano_Semestre & \multicolumn{5}{|c|}{ Nota } \\
\hline 2003_01 & $21 \%$ & $41 \%$ & $37 \%$ & $1 \%$ & $100 \%$ \\
\hline 2006_02 & $22 \%$ & $43 \%$ & $34 \%$ & $1 \%$ & $100 \%$ \\
\hline 2007_02 & $23 \%$ & $42 \%$ & $35 \%$ & $1 \%$ & $100 \%$ \\
\hline 2008_01 & $25 \%$ & $41 \%$ & $33 \%$ & $1 \%$ & $100 \%$ \\
\hline 2008_02 & $22 \%$ & $42 \%$ & $34 \%$ & $1 \%$ & $100 \%$ \\
\hline 2009_01 & $22 \%$ & $42 \%$ & $34 \%$ & $2 \%$ & $100 \%$ \\
\hline Total & $22 \%$ & $42 \%$ & $35 \%$ & $1 \%$ & $100 \%$ \\
\hline
\end{tabular}

Qualidade na transmissão do conteúdo

\begin{tabular}{|c|c|c|c|c|c|}
\hline Ano_Semestre & \multicolumn{5}{|c|}{ Nota } \\
\hline 2003_01 & $67 \%$ & $29 \%$ & $3 \%$ & $1 \%$ & $100 \%$ \\
\hline 2006_02 & $66 \%$ & $30 \%$ & $3 \%$ & $1 \%$ & $100 \%$ \\
\hline 2007_02 & $67 \%$ & $30 \%$ & $3 \%$ & $0 \%$ & $100 \%$ \\
\hline 2008_01 & $67 \%$ & $29 \%$ & $4 \%$ & $1 \%$ & $100 \%$ \\
\hline 2008_02 & $68 \%$ & $29 \%$ & $3 \%$ & $1 \%$ & $100 \%$ \\
\hline 2009_01 & $68 \%$ & $28 \%$ & $3 \%$ & $1 \%$ & $100 \%$ \\
\hline Total & $67 \%$ & $29 \%$ & $3 \%$ & $1 \%$ & $100 \%$ \\
\hline
\end{tabular}

Entusiasmo demonstrado na transmissão do conteúdo 


\begin{tabular}{|c|c|c|c|c|c|}
\hline Ano_Semestre & \multicolumn{5}{|c|}{ Nota } \\
\hline 2003_01 & $61 \%$ & $32 \%$ & $6 \%$ & $1 \%$ & $100 \%$ \\
\hline 2006_02 & $62 \%$ & $31 \%$ & $5 \%$ & $1 \%$ & $100 \%$ \\
\hline 2007_02 & $60 \%$ & $34 \%$ & $6 \%$ & $0 \%$ & $100 \%$ \\
\hline 2008_01 & $60 \%$ & $32 \%$ & $7 \%$ & $1 \%$ & $100 \%$ \\
\hline 2008_02 & $59 \%$ & $33 \%$ & $7 \%$ & $1 \%$ & $100 \%$ \\
\hline 2009_01 & $59 \%$ & $32 \%$ & $7 \%$ & $1 \%$ & $100 \%$ \\
\hline Total & $60 \%$ & $32 \%$ & $6 \%$ & $1 \%$ & $100 \%$ \\
\hline
\end{tabular}

Incentivo à participação dos alunos nas atividades previstas no programa da disciplina

\begin{tabular}{|c|c|c|c|c|c|}
\hline Ano_Semestre & \multicolumn{5}{|c|}{ Nota } \\
\hline 2003_01 & $69 \%$ & $26 \%$ & $3 \%$ & $2 \%$ & $100 \%$ \\
\hline 2006_02 & $68 \%$ & $26 \%$ & $3 \%$ & $2 \%$ & $100 \%$ \\
\hline 2007_02 & $66 \%$ & $29 \%$ & $3 \%$ & $2 \%$ & $100 \%$ \\
\hline 2008_01 & $65 \%$ & $29 \%$ & $3 \%$ & $3 \%$ & $100 \%$ \\
\hline 2008_02 & $67 \%$ & $27 \%$ & $3 \%$ & $3 \%$ & $100 \%$ \\
\hline 2009_01 & $67 \%$ & $27 \%$ & $3 \%$ & $3 \%$ & $100 \%$ \\
\hline Total & $67 \%$ & $27 \%$ & $3 \%$ & $2 \%$ & $100 \%$ \\
\hline
\end{tabular}

Incentivo, ao aluno, à realização de atividades adicionais de aprofundamento do aprendizado

\begin{tabular}{|c|c|c|c|c|c|}
\hline Ano_Semestre & \multicolumn{5}{|c|}{ Nota } \\
\hline 2003_01 & $77 \%$ & $18 \%$ & $2 \%$ & $3 \%$ & $100 \%$ \\
\hline 2006_02 & $75 \%$ & $18 \%$ & $2 \%$ & $5 \%$ & $100 \%$ \\
\hline 2007_02 & $74 \%$ & $21 \%$ & $2 \%$ & $4 \%$ & $100 \%$ \\
\hline 2008_01 & $73 \%$ & $20 \%$ & $3 \%$ & $5 \%$ & $100 \%$ \\
\hline 2008_02 & $74 \%$ & $19 \%$ & $2 \%$ & $5 \%$ & $100 \%$ \\
\hline 2009_01 & $73 \%$ & $20 \%$ & $3 \%$ & $4 \%$ & $100 \%$ \\
\hline Total & $74 \%$ & $19 \%$ & $2 \%$ & $4 \%$ & $100 \%$ \\
\hline
\end{tabular}

Uso de estratégias para motivar os alunos em relação ao conteúdo

\begin{tabular}{|c|c|c|c|c|c|}
\hline \multirow{2}{*}{ Ano_Semestre } & \multicolumn{5}{|c|}{ Nota } \\
\hline & 0 a 6 & 7 a 8 & 9 a 10 & $\mathrm{~m}$ is & Total \\
\hline 2003_01 & $88 \%$ & $9 \%$ & $0 \%$ & $2 \%$ & $100 \%$ \\
\hline 2006_02 & $87 \%$ & $9 \%$ & $1 \%$ & $4 \%$ & $100 \%$ \\
\hline 2007_02 & $88 \%$ & $10 \%$ & $1 \%$ & $2 \%$ & $100 \%$ \\
\hline 2008_01 & $87 \%$ & $10 \%$ & $1 \%$ & $2 \%$ & $100 \%$ \\
\hline 2008_02 & $87 \%$ & $10 \%$ & $0 \%$ & $2 \%$ & $100 \%$ \\
\hline 2009_01 & $88 \%$ & $9 \%$ & $0 \%$ & $3 \%$ & $100 \%$ \\
\hline Total & $88 \%$ & $10 \%$ & $1 \%$ & $2 \%$ & $100 \%$ \\
\hline
\end{tabular}

Ritmo de apresentação do conteúdo 


\begin{tabular}{|c|c|c|c|c|c|}
\hline Ano_Semestre & \multicolumn{5}{|c|}{ Nota } \\
\hline 2003_01 & $76 \%$ & $20 \%$ & $2 \%$ & $2 \%$ & $100 \%$ \\
\hline 2006_02 & $74 \%$ & $21 \%$ & $2 \%$ & $3 \%$ & $100 \%$ \\
\hline 2007_02 & $73 \%$ & $23 \%$ & $2 \%$ & $1 \%$ & $100 \%$ \\
\hline 2008_01 & $74 \%$ & $23 \%$ & $3 \%$ & $1 \%$ & $100 \%$ \\
\hline 2008_02 & $74 \%$ & $22 \%$ & $2 \%$ & $1 \%$ & $100 \%$ \\
\hline 2009_01 & $73 \%$ & $22 \%$ & $3 \%$ & $2 \%$ & $100 \%$ \\
\hline Total & $74 \%$ & $22 \%$ & $2 \%$ & $2 \%$ & $100 \%$ \\
\hline
\end{tabular}

Adequação das atividades desenvolvidas para o alcance dos objetivos propostos

\begin{tabular}{|c|c|c|c|c|c|}
\hline Ano_Semestre & \multicolumn{5}{|c|}{ Nota } \\
\hline 2003_01 & $71 \%$ & $25 \%$ & $1 \%$ & $2 \%$ & $100 \%$ \\
\hline 2006_02 & $70 \%$ & $25 \%$ & $1 \%$ & $3 \%$ & $100 \%$ \\
\hline 2007_02 & $70 \%$ & $26 \%$ & $2 \%$ & $2 \%$ & $100 \%$ \\
\hline 2008_01 & $71 \%$ & $25 \%$ & $1 \%$ & $2 \%$ & $100 \%$ \\
\hline 2008_02 & $71 \%$ & $25 \%$ & $1 \%$ & $3 \%$ & $100 \%$ \\
\hline 2009_01 & $70 \%$ & $25 \%$ & $2 \%$ & $3 \%$ & $100 \%$ \\
\hline Total & $71 \%$ & $25 \%$ & $1 \%$ & $3 \%$ & $100 \%$ \\
\hline
\end{tabular}

Profundidade com que o conteúdo foi abordado, considerando os objetivos da disciplina

\begin{tabular}{|c|c|c|c|c|c|}
\hline Ano_Semestre & \multicolumn{5}{|c|}{ Nota } \\
\hline 2003_01 & $64 \%$ & $30 \%$ & $4 \%$ & $2 \%$ & $100 \%$ \\
\hline 2006_02 & $64 \%$ & $30 \%$ & $4 \%$ & $3 \%$ & $100 \%$ \\
\hline 2007_02 & $62 \%$ & $32 \%$ & $4 \%$ & $2 \%$ & $100 \%$ \\
\hline 2008_01 & $65 \%$ & $30 \%$ & $4 \%$ & $2 \%$ & $100 \%$ \\
\hline 2008_02 & $64 \%$ & $30 \%$ & $4 \%$ & $2 \%$ & $100 \%$ \\
\hline 2009_01 & $63 \%$ & $30 \%$ & $5 \%$ & $2 \%$ & $100 \%$ \\
\hline Total & $64 \%$ & $30 \%$ & $4 \%$ & $2 \%$ & $100 \%$ \\
\hline
\end{tabular}

Integração do conteúdo da disciplina com conteúdos conexos de outras disciplinas

\begin{tabular}{|c|c|c|c|c|c|}
\hline Ano_Semestre & \multicolumn{5}{|c|}{ Nota } \\
\hline 2003_01 & $62 \%$ & $29 \%$ & $5 \%$ & $5 \%$ & $100 \%$ \\
\hline 2006_02 & $62 \%$ & $28 \%$ & $5 \%$ & $5 \%$ & $100 \%$ \\
\hline 2007_02 & $59 \%$ & $31 \%$ & $6 \%$ & $4 \%$ & $100 \%$ \\
\hline 2008_01 & $62 \%$ & $29 \%$ & $5 \%$ & $5 \%$ & $100 \%$ \\
\hline 2008_02 & $60 \%$ & $30 \%$ & $5 \%$ & $4 \%$ & $100 \%$ \\
\hline 2009_01 & $61 \%$ & $30 \%$ & $5 \%$ & $4 \%$ & $100 \%$ \\
\hline Total & $61 \%$ & $29 \%$ & $5 \%$ & $5 \%$ & $100 \%$ \\
\hline
\end{tabular}

Integração entre teoria, pesquisa e/ou aspectos da realidade 


\begin{tabular}{|c|c|c|c|c|c|}
\hline Ano_Semestre & \multicolumn{5}{|c|}{ Nota } \\
\hline 2003_01 & $62 \%$ & $28 \%$ & $4 \%$ & $6 \%$ & $100 \%$ \\
\hline 2006_02 & $61 \%$ & $27 \%$ & $5 \%$ & $7 \%$ & $100 \%$ \\
\hline 2007_02 & $59 \%$ & $30 \%$ & $5 \%$ & $6 \%$ & $100 \%$ \\
\hline 2008_01 & $59 \%$ & $29 \%$ & $5 \%$ & $7 \%$ & $100 \%$ \\
\hline 2008_02 & $61 \%$ & $28 \%$ & $5 \%$ & $7 \%$ & $100 \%$ \\
\hline 2009_01 & $62 \%$ & $28 \%$ & $4 \%$ & $6 \%$ & $100 \%$ \\
\hline Total & $61 \%$ & $29 \%$ & $4 \%$ & $6 \%$ & $100 \%$ \\
\hline
\end{tabular}

Qualidade dos exemplos utilizados para relacionar teoria, pesquisa e prática

\begin{tabular}{|c|c|c|c|c|c|}
\hline Ano_Semestre & \multicolumn{5}{|c|}{ Nota } \\
\hline 2003_01 & $62 \%$ & $29 \%$ & $4 \%$ & $5 \%$ & $100 \%$ \\
\hline 2006_02 & $64 \%$ & $28 \%$ & $3 \%$ & $5 \%$ & $100 \%$ \\
\hline 2007_02 & $60 \%$ & $31 \%$ & $4 \%$ & $6 \%$ & $100 \%$ \\
\hline 2008_01 & $62 \%$ & $30 \%$ & $4 \%$ & $4 \%$ & $100 \%$ \\
\hline 2008_02 & $62 \%$ & $31 \%$ & $4 \%$ & $4 \%$ & $100 \%$ \\
\hline 2009_01 & $63 \%$ & $30 \%$ & $3 \%$ & $4 \%$ & $100 \%$ \\
\hline Total & $62 \%$ & $30 \%$ & $3 \%$ & $5 \%$ & $100 \%$ \\
\hline
\end{tabular}

Coerência entre nível de complexidade das avaliações e o conteúdo ministrado

\begin{tabular}{|c|c|c|c|c|c|}
\hline Ano_Semestre & 0 a 6 & 7 a 8 & $\begin{array}{c}\text { Nota } \\
9 \text { a } 10\end{array}$ & $\mathrm{~m}$ is & Total \\
\hline 2003_01 & $58 \%$ & $28 \%$ & $9 \%$ & $4 \%$ & $100 \%$ \\
\hline 2006_02 & $59 \%$ & $30 \%$ & $8 \%$ & $3 \%$ & $100 \%$ \\
\hline 2007_02 & $61 \%$ & $28 \%$ & $8 \%$ & $3 \%$ & $100 \%$ \\
\hline 2008_01 & $61 \%$ & $29 \%$ & $8 \%$ & $2 \%$ & $100 \%$ \\
\hline 2008_02 & $61 \%$ & $28 \%$ & $7 \%$ & $3 \%$ & $100 \%$ \\
\hline 2009_01 & $60 \%$ & $29 \%$ & $8 \%$ & $4 \%$ & $100 \%$ \\
\hline Total & $60 \%$ & $29 \%$ & $8 \%$ & $3 \%$ & $100 \%$ \\
\hline
\end{tabular}

Discussão dos resultados de avaliações de aprendizagem

\begin{tabular}{|c|c|c|c|c|c|}
\hline Ano_Semestre & 0 a 6 & 7 a 8 & $\begin{array}{c}\text { Nota } \\
9 \text { a } 10\end{array}$ & $\mathrm{~m}$ is & Total \\
\hline 2003_01 & $73 \%$ & $17 \%$ & $3 \%$ & $8 \%$ & $100 \%$ \\
\hline 2006_02 & $69 \%$ & $20 \%$ & $3 \%$ & $8 \%$ & $100 \%$ \\
\hline 2007_02 & $71 \%$ & $20 \%$ & $3 \%$ & $7 \%$ & $100 \%$ \\
\hline 2008_01 & $70 \%$ & $21 \%$ & $3 \%$ & $6 \%$ & $100 \%$ \\
\hline 2008_02 & $70 \%$ & $20 \%$ & $3 \%$ & $7 \%$ & $100 \%$ \\
\hline 2009_01 & $70 \%$ & $19 \%$ & $3 \%$ & $8 \%$ & $100 \%$ \\
\hline Total & $71 \%$ & $19 \%$ & $3 \%$ & $7 \%$ & $100 \%$ \\
\hline
\end{tabular}

Adequação do uso dos recursos de ensino 


\begin{tabular}{|c|c|c|c|c|c|}
\hline Ano_Semestre & \multicolumn{5}{|c|}{ Nota } \\
\hline 2003_01 & $57 \%$ & $29 \%$ & $9 \%$ & $5 \%$ & $100 \%$ \\
\hline 2006_02 & $52 \%$ & $32 \%$ & $10 \%$ & $6 \%$ & $100 \%$ \\
\hline 2007_02 & $52 \%$ & $32 \%$ & $11 \%$ & $5 \%$ & $100 \%$ \\
\hline 2008_01 & $50 \%$ & $34 \%$ & $12 \%$ & $4 \%$ & $100 \%$ \\
\hline 2008_02 & $49 \%$ & $34 \%$ & $13 \%$ & $5 \%$ & $100 \%$ \\
\hline 2009_01 & $47 \%$ & $34 \%$ & $14 \%$ & $5 \%$ & $100 \%$ \\
\hline Total & $52 \%$ & $32 \%$ & $11 \%$ & $5 \%$ & $100 \%$ \\
\hline
\end{tabular}

Disponibilidade para esclarecer dúvidas e solucionar dificuldades dos alunos, relacionadas ao conteúdo da disciplina

\begin{tabular}{|c|c|c|c|c|c|}
\hline Ano_Semestre & 0 a 6 & 7 a 8 & $\begin{array}{c}\text { Nota } \\
9 \text { a } 10 \\
\end{array}$ & $\mathrm{~m}$ is & Total \\
\hline 2003_01 & $54 \%$ & $32 \%$ & $9 \%$ & $4 \%$ & $100 \%$ \\
\hline 2006_02 & $52 \%$ & $32 \%$ & $10 \%$ & $6 \%$ & $100 \%$ \\
\hline 2007_02 & $53 \%$ & $31 \%$ & $10 \%$ & $6 \%$ & $100 \%$ \\
\hline 2008_01 & $50 \%$ & $33 \%$ & $11 \%$ & $6 \%$ & $100 \%$ \\
\hline 2008_02 & $51 \%$ & $32 \%$ & $11 \%$ & $6 \%$ & $100 \%$ \\
\hline 2009_01 & $53 \%$ & $32 \%$ & $10 \%$ & $5 \%$ & $100 \%$ \\
\hline Total & $52 \%$ & $32 \%$ & $10 \%$ & $5 \%$ & $100 \%$ \\
\hline
\end{tabular}

Cordialidade na relação com os alunos

\begin{tabular}{|c|c|c|c|c|c|}
\hline Ano_Semestre & \multicolumn{5}{|c|}{ Nota } \\
\hline 2003_01 & $37 \%$ & $34 \%$ & $27 \%$ & $1 \%$ & $100 \%$ \\
\hline 2006_02 & $39 \%$ & $35 \%$ & $25 \%$ & $1 \%$ & $100 \%$ \\
\hline 2007_02 & $40 \%$ & $34 \%$ & $25 \%$ & $1 \%$ & $100 \%$ \\
\hline 2008_01 & $39 \%$ & $35 \%$ & $24 \%$ & $1 \%$ & $100 \%$ \\
\hline 2008_02 & $39 \%$ & $34 \%$ & $26 \%$ & $1 \%$ & $100 \%$ \\
\hline 2009_01 & $39 \%$ & $34 \%$ & $26 \%$ & $1 \%$ & $100 \%$ \\
\hline Total & $39 \%$ & $34 \%$ & $26 \%$ & $1 \%$ & $100 \%$ \\
\hline
\end{tabular}

Respeito às idéias manifestadas pelos alunos acerca dos temas abordados

\begin{tabular}{|c|c|c|c|c|c|}
\hline Ano_Semestre & \multicolumn{5}{|c|}{ Nota } \\
\hline 2003_01 & $35 \%$ & $37 \%$ & $24 \%$ & $4 \%$ & $100 \%$ \\
\hline 2006_02 & $36 \%$ & $38 \%$ & $24 \%$ & $3 \%$ & $100 \%$ \\
\hline 2007_02 & $37 \%$ & $37 \%$ & $24 \%$ & $2 \%$ & $100 \%$ \\
\hline 2008_01 & $39 \%$ & $35 \%$ & $24 \%$ & $2 \%$ & $100 \%$ \\
\hline 2008_02 & $36 \%$ & $36 \%$ & $25 \%$ & $2 \%$ & $100 \%$ \\
\hline 2009_01 & $37 \%$ & $37 \%$ & $24 \%$ & $3 \%$ & $100 \%$ \\
\hline Total & $37 \%$ & $37 \%$ & $24 \%$ & $3 \%$ & $100 \%$ \\
\hline
\end{tabular}

Disponibilidade para atendimento extra-classe 


\begin{tabular}{|c|c|c|c|c|c|}
\hline Ano_Semestre & \multicolumn{5}{|c|}{ Nota } \\
\hline 2003_01 & $52 \%$ & $27 \%$ & $10 \%$ & $11 \%$ & $100 \%$ \\
\hline 2006_02 & $48 \%$ & $25 \%$ & $9 \%$ & $18 \%$ & $100 \%$ \\
\hline 2007_02 & $49 \%$ & $25 \%$ & $9 \%$ & $18 \%$ & $100 \%$ \\
\hline 2008_01 & $50 \%$ & $24 \%$ & $10 \%$ & $16 \%$ & $100 \%$ \\
\hline 2008_02 & $49 \%$ & $25 \%$ & $10 \%$ & $17 \%$ & $100 \%$ \\
\hline 2009_01 & $50 \%$ & $24 \%$ & $10 \%$ & $16 \%$ & $100 \%$ \\
\hline Total & $50 \%$ & $25 \%$ & $10 \%$ & $15 \%$ & $100 \%$ \\
\hline
\end{tabular}

Cumprimento dos horários de início e término das aulas, pelo professor

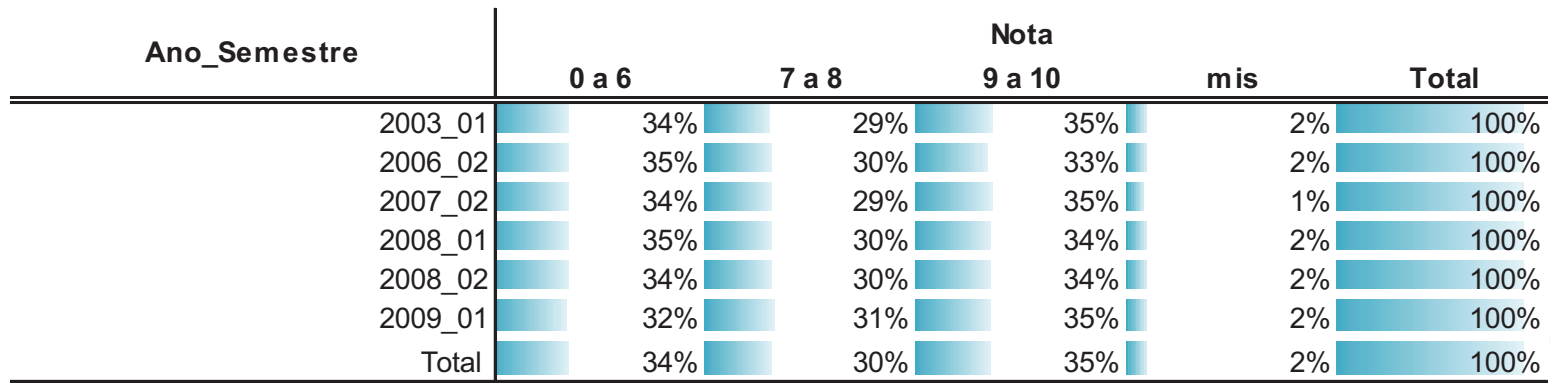

Assiduidade

\begin{tabular}{|c|c|c|c|c|c|}
\hline Ano_Semestre & 0 a 6 & 7 a 8 & $\begin{array}{c}\text { Nota } \\
9 \text { a } 10\end{array}$ & $\mathrm{~m}$ is & Total \\
\hline 2003_01 & $23 \%$ & $24 \%$ & $50 \%$ & $3 \%$ & $100 \%$ \\
\hline $2006 \_02$ & $25 \%$ & $26 \%$ & $47 \%$ & $3 \%$ & $100 \%$ \\
\hline 2007_02 & $24 \%$ & $27 \%$ & $47 \%$ & $2 \%$ & $100 \%$ \\
\hline 2008_01 & $26 \%$ & $27 \%$ & $44 \%$ & $3 \%$ & $100 \%$ \\
\hline 2008_02 & $26 \%$ & $26 \%$ & $46 \%$ & $2 \%$ & $100 \%$ \\
\hline 2009_01 & $23 \%$ & $28 \%$ & $46 \%$ & $3 \%$ & $100 \%$ \\
\hline Total & $24 \%$ & $26 \%$ & $47 \%$ & $3 \%$ & $100 \%$ \\
\hline
\end{tabular}

\section{Apêndice C - tabelas cluster satisfeito}

Domínio do conteúdo ministrado

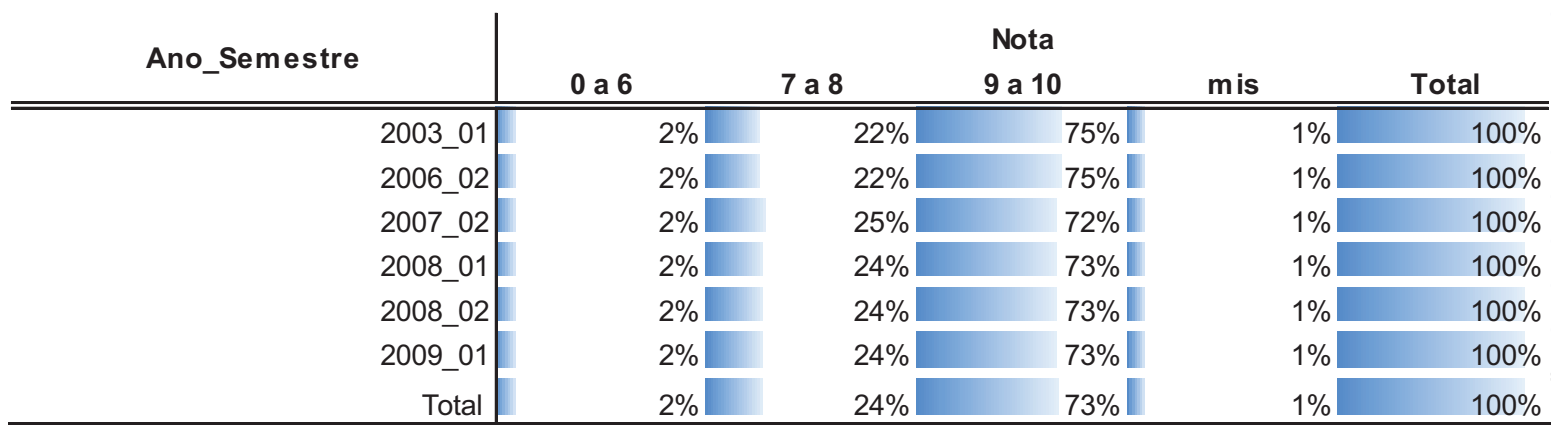

Qualidade na transmissão do conteúdo 


\begin{tabular}{|c|c|c|c|c|c|}
\hline Ano_Semestre & \multicolumn{5}{|c|}{ Nota } \\
\hline 2003_01 & $\overline{11 \%}$ & $46 \%$ & $42 \%$ & $1 \%$ & $100 \%$ \\
\hline 2006_02 & $10 \%$ & $48 \%$ & $42 \%$ & $1 \%$ & $100 \%$ \\
\hline 2007_02 & $10 \%$ & $49 \%$ & $39 \%$ & $1 \%$ & $100 \%$ \\
\hline 2008_01 & $11 \%$ & $48 \%$ & $40 \%$ & $1 \%$ & $100 \%$ \\
\hline 2008_02 & $11 \%$ & $49 \%$ & $40 \%$ & $1 \%$ & $100 \%$ \\
\hline 2009_01 & $11 \%$ & $48 \%$ & $40 \%$ & $1 \%$ & $100 \%$ \\
\hline Total & $11 \%$ & $48 \%$ & $40 \%$ & $1 \%$ & $100 \%$ \\
\hline
\end{tabular}

Entusiasmo demonstrado na transmissão do conteúdo

\begin{tabular}{|c|c|c|c|c|c|}
\hline Ano_Semestre & 0 a 6 & 7 a 8 & $\begin{array}{c}\text { Nota } \\
9 \text { a } 10\end{array}$ & $\mathrm{~m}$ is & Total \\
\hline 2003_01 & $8 \%$ & $43 \%$ & $48 \%$ & $1 \%$ & $100 \%$ \\
\hline 2006_02 & $8 \%$ & $41 \%$ & $50 \%$ & $1 \%$ & $100 \%$ \\
\hline 2007_02 & $9 \%$ & $44 \%$ & $47 \%$ & $1 \%$ & $100 \%$ \\
\hline 2008_01 & $8 \%$ & $42 \%$ & $49 \%$ & $1 \%$ & $100 \%$ \\
\hline 2008_02 & $8 \%$ & $43 \%$ & $49 \%$ & $1 \%$ & $100 \%$ \\
\hline 2009_01 & $9 \%$ & $42 \%$ & $48 \%$ & $1 \%$ & $100 \%$ \\
\hline Total & $8 \%$ & $43 \%$ & $48 \%$ & $1 \%$ & $100 \%$ \\
\hline
\end{tabular}

Incentivo à participação dos alunos nas atividades previstas no programa da disciplina

\begin{tabular}{|c|c|c|c|c|c|}
\hline Ano_Semestre & \multicolumn{5}{|c|}{ Nota } \\
\hline 2003_01 & $12 \%$ & $51 \%$ & $34 \%$ & $2 \%$ & $100 \%$ \\
\hline 2006_02 & $11 \%$ & $52 \%$ & $34 \%$ & $3 \%$ & $100 \%$ \\
\hline 2007_02 & $11 \%$ & $53 \%$ & $34 \%$ & $2 \%$ & $100 \%$ \\
\hline 2008_01 & $11 \%$ & $52 \%$ & $35 \%$ & $2 \%$ & $100 \%$ \\
\hline 2008_02 & $10 \%$ & $52 \%$ & $35 \%$ & $2 \%$ & $100 \%$ \\
\hline 2009_01 & $11 \%$ & $52 \%$ & $34 \%$ & $3 \%$ & $100 \%$ \\
\hline Total & $11 \%$ & $52 \%$ & $35 \%$ & $2 \%$ & $100 \%$ \\
\hline
\end{tabular}

Incentivo, ao aluno, à realização de atividades adicionais de aprofundamento do aprendizado

\begin{tabular}{|c|c|c|c|c|c|}
\hline Ano_Semestre & \multicolumn{5}{|c|}{ Nota } \\
\hline 2003_01 & $23 \%$ & $51 \%$ & $22 \%$ & $4 \%$ & $100 \%$ \\
\hline 2006_02 & $20 \%$ & $51 \%$ & $24 \%$ & $5 \%$ & $100 \%$ \\
\hline 2007_02 & $19 \%$ & $54 \%$ & $22 \%$ & $5 \%$ & $100 \%$ \\
\hline 2008_01 & $19 \%$ & $52 \%$ & $24 \%$ & $5 \%$ & $100 \%$ \\
\hline 2008_02 & $18 \%$ & $53 \%$ & $24 \%$ & $5 \%$ & $100 \%$ \\
\hline 2009_01 & $19 \%$ & $52 \%$ & $24 \%$ & $5 \%$ & $100 \%$ \\
\hline Total & $20 \%$ & $52 \%$ & $23 \%$ & $5 \%$ & $100 \%$ \\
\hline
\end{tabular}

Uso de estratégias para motivar os alunos em relação ao conteúdo 


\begin{tabular}{|c|c|c|c|c|c|}
\hline Ano_Semestre & \multicolumn{5}{|c|}{ Nota } \\
\hline 2003_01. & $30 \%$ & $54 \%$ & $15 \%$ & $2 \%$ & $100 \%$ \\
\hline 2006_02 & $27 \%$ & $55 \%$ & $15 \%$ & $2 \%$ & $100 \%$ \\
\hline 2007_02 & $26 \%$ & $57 \%$ & $14 \%$ & $2 \%$ & $100 \%$ \\
\hline 2008_01 & $26 \%$ & $56 \%$ & $15 \%$ & $2 \%$ & $100 \%$ \\
\hline 2008_02 & $26 \%$ & $56 \%$ & $16 \%$ & $3 \%$ & $100 \%$ \\
\hline 2009_01 & $26 \%$ & $56 \%$ & $16 \%$ & $3 \%$ & $100 \%$ \\
\hline Total & $27 \%$ & $56 \%$ & $15 \%$ & $2 \%$ & $100 \%$ \\
\hline
\end{tabular}

Ritmo de apresentação do conteúdo

\begin{tabular}{|c|c|c|c|c|c|}
\hline Ano_Semestre & \multicolumn{5}{|c|}{ Nota } \\
\hline 2003_01 & $21 \%$ & 53\% & $25 \%$ & $2 \%$ & $100 \%$ \\
\hline 2006_02 & $19 \%$ & $55 \%$ & $25 \%$ & $1 \%$ & $100 \%$ \\
\hline 2007_02 & $19 \%$ & $55 \%$ & $25 \%$ & $1 \%$ & $100 \%$ \\
\hline 2008_01 & $19 \%$ & $54 \%$ & $26 \%$ & $1 \%$ & $100 \%$ \\
\hline 2008_02 & $18 \%$ & $55 \%$ & $25 \%$ & $1 \%$ & $100 \%$ \\
\hline 2009_01 & $18 \%$ & $55 \%$ & $26 \%$ & $2 \%$ & $100 \%$ \\
\hline Total & $19 \%$ & $54 \%$ & $25 \%$ & $1 \%$ & $100 \%$ \\
\hline
\end{tabular}

Adequação das atividades desenvolvidas para o alcance dos objetivos propostos

\begin{tabular}{|c|c|c|c|c|c|}
\hline Ano_Semestre & \multicolumn{5}{|c|}{ Nota } \\
\hline 2003_01 & $11 \%$ & $58 \%$ & $29 \%$ & $2 \%$ & $100 \%$ \\
\hline 2006_02 & $10 \%$ & $58 \%$ & $29 \%$ & $2 \%$ & $100 \%$ \\
\hline 2007_02 & $9 \%$ & $59 \%$ & $30 \%$ & $2 \%$ & $100 \%$ \\
\hline 2008_01 & $10 \%$ & $57 \%$ & $31 \%$ & $2 \%$ & $100 \%$ \\
\hline 2008_02 & $9 \%$ & $59 \%$ & $30 \%$ & $2 \%$ & $100 \%$ \\
\hline 2009_01 & $10 \%$ & $58 \%$ & $30 \%$ & $2 \%$ & $100 \%$ \\
\hline Total & $10 \%$ & $58 \%$ & $30 \%$ & $2 \%$ & $100 \%$ \\
\hline
\end{tabular}

Profundidade com que o conteúdo foi abordado, considerando os objetivos da disciplina

\begin{tabular}{|c|c|c|c|c|c|}
\hline Ano_Semestre & 0 a 6 & 7 a 8 & $\begin{array}{c}\text { Nota } \\
9 \text { a } 10 \\
\end{array}$ & $\mathrm{~m}$ is & Total \\
\hline 2003_01 & $12 \%$ & $\overline{51 \%}$ & $35 \%$ & $2 \%$ & $100 \%$ \\
\hline 2006_02 & $12 \%$ & $51 \%$ & $36 \%$ & $1 \%$ & $100 \%$ \\
\hline 2007_02 & $11 \%$ & $52 \%$ & $35 \%$ & $2 \%$ & $100 \%$ \\
\hline 2008_01 & $12 \%$ & $51 \%$ & $36 \%$ & $1 \%$ & $100 \%$ \\
\hline 2008_02 & $11 \%$ & $53 \%$ & $34 \%$ & $2 \%$ & $100 \%$ \\
\hline 2009_01 & $11 \%$ & $51 \%$ & $35 \%$ & $2 \%$ & $100 \%$ \\
\hline Total & $11 \%$ & $52 \%$ & $35 \%$ & $2 \%$ & $100 \%$ \\
\hline
\end{tabular}

Integração do conteúdo da disciplina com conteúdos conexos de outras disciplinas 


\begin{tabular}{|c|c|c|c|c|c|}
\hline Ano_Semestre & \multicolumn{5}{|c|}{ Nota } \\
\hline 2003_01 & $\overline{17 \%}$ & $49 \%$ & $30 \%$ & $5 \%$ & $100 \%$ \\
\hline 2006_02 & $16 \%$ & $48 \%$ & $32 \%$ & $5 \%$ & $100 \%$ \\
\hline 2007_02 & $14 \%$ & $50 \%$ & $32 \%$ & $5 \%$ & $100 \%$ \\
\hline 2008_01 & $14 \%$ & $49 \%$ & $33 \%$ & $4 \%$ & $100 \%$ \\
\hline 2008_02 & $13 \%$ & $50 \%$ & $32 \%$ & $5 \%$ & $100 \%$ \\
\hline 2009_01 & $14 \%$ & $49 \%$ & $32 \%$ & $5 \%$ & $100 \%$ \\
\hline Total & $15 \%$ & $49 \%$ & $32 \%$ & $5 \%$ & $100 \%$ \\
\hline
\end{tabular}

Integração entre teoria, pesquisa e/ou aspectos da realidade

\begin{tabular}{|c|c|c|c|c|c|}
\hline Ano_Semestre & \multicolumn{5}{|c|}{ Nota } \\
\hline 2003_01 & $14 \%$ & $48 \%$ & $33 \%$ & $5 \%$ & $100 \%$ \\
\hline 2006_02 & $13 \%$ & $48 \%$ & $34 \%$ & $6 \%$ & $100 \%$ \\
\hline 2007_02 & $12 \%$ & $49 \%$ & $34 \%$ & $6 \%$ & $100 \%$ \\
\hline 2008_01 & $11 \%$ & $48 \%$ & $35 \%$ & $6 \%$ & $100 \%$ \\
\hline 2008_02 & $12 \%$ & $48 \%$ & $34 \%$ & $7 \%$ & $100 \%$ \\
\hline 2009_01 & $12 \%$ & $48 \%$ & $33 \%$ & $7 \%$ & $100 \%$ \\
\hline Total & $12 \%$ & $48 \%$ & $34 \%$ & $6 \%$ & $100 \%$ \\
\hline
\end{tabular}

Qualidade dos exemplos utilizados para relacionar teoria, pesquisa e prática

\begin{tabular}{|c|c|c|c|c|c|}
\hline Ano_Semestre & \multicolumn{5}{|c|}{ Nota } \\
\hline 2003_01 & $11 \%$ & $48 \%$ & $36 \%$ & $5 \%$ & $100 \%$ \\
\hline 2006_02 & $9 \%$ & $49 \%$ & $37 \%$ & $4 \%$ & $100 \%$ \\
\hline 2007_02 & $9 \%$ & $50 \%$ & $36 \%$ & $5 \%$ & $100 \%$ \\
\hline 2008_01 & $9 \%$ & $50 \%$ & $37 \%$ & $4 \%$ & $100 \%$ \\
\hline 2008_02 & $9 \%$ & $50 \%$ & $36 \%$ & $5 \%$ & $100 \%$ \\
\hline 2009_01 & $9 \%$ & $49 \%$ & $37 \%$ & $5 \%$ & $100 \%$ \\
\hline Total & $10 \%$ & $49 \%$ & $37 \%$ & $5 \%$ & $100 \%$ \\
\hline
\end{tabular}

Coerência entre nível de complexidade das avaliações e o conteúdo ministrado

\begin{tabular}{|c|c|c|c|c|c|}
\hline Ano_Semestre & \multicolumn{5}{|c|}{ Nota } \\
\hline 2003_01 & $16 \%$ & 41\% & $39 \%$ & $4 \%$ & $100 \%$ \\
\hline 2006_02 & $14 \%$ & $43 \%$ & $40 \%$ & $3 \%$ & $100 \%$ \\
\hline 2007_02 & $14 \%$ & $45 \%$ & $39 \%$ & $2 \%$ & $100 \%$ \\
\hline 2008_01 & $14 \%$ & $44 \%$ & $39 \%$ & $3 \%$ & $100 \%$ \\
\hline 2008_02 & $14 \%$ & $45 \%$ & $38 \%$ & $3 \%$ & $100 \%$ \\
\hline 2009_01 & $15 \%$ & $45 \%$ & $37 \%$ & $3 \%$ & $100 \%$ \\
\hline Total & $15 \%$ & $44 \%$ & $39 \%$ & $3 \%$ & $100 \%$ \\
\hline
\end{tabular}


Discussão dos resultados de avaliações de aprendizagem

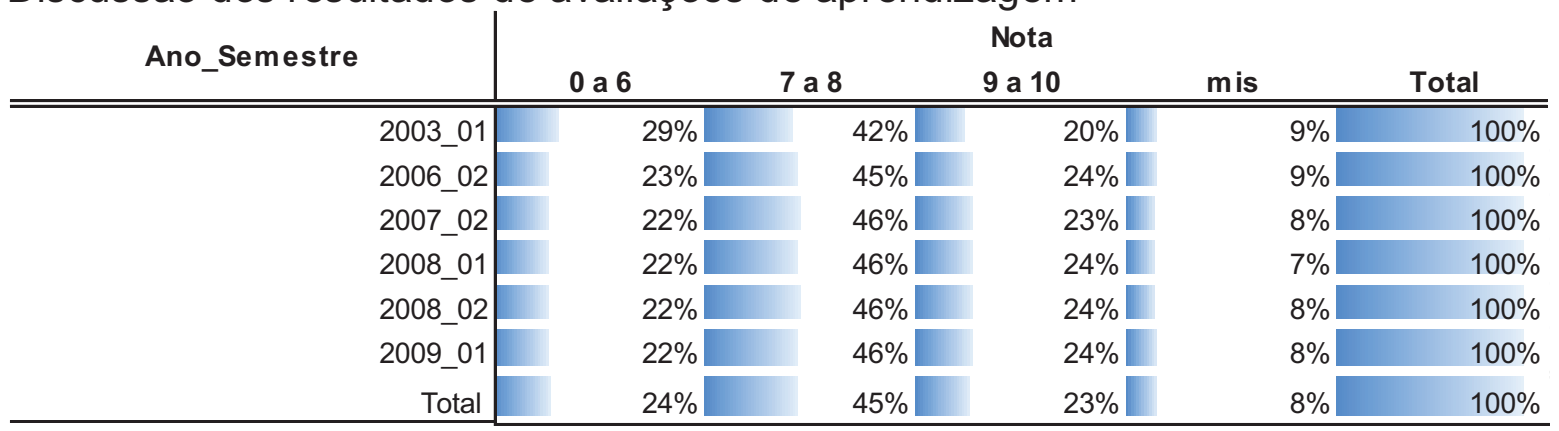

Adequação do uso dos recursos de ensino

\begin{tabular}{|c|c|c|c|c|c|}
\hline Ano_Semestre & \multicolumn{5}{|c|}{ Nota } \\
\hline 2003_01 & $19 \%$ & $43 \%$ & $33 \%$ & $5 \%$ & $100 \%$ \\
\hline 2006_02 & $15 \%$ & $43 \%$ & $37 \%$ & $6 \%$ & $100 \%$ \\
\hline 2007_02 & $15 \%$ & $44 \%$ & $36 \%$ & $5 \%$ & $100 \%$ \\
\hline 2008_01 & $13 \%$ & $45 \%$ & $38 \%$ & $4 \%$ & $100 \%$ \\
\hline 2008_02 & $13 \%$ & $44 \%$ & $38 \%$ & $5 \%$ & $100 \%$ \\
\hline 2009_01 & $13 \%$ & $42 \%$ & $40 \%$ & $5 \%$ & $100 \%$ \\
\hline Total & $15 \%$ & $43 \%$ & $37 \%$ & $5 \%$ & $100 \%$ \\
\hline
\end{tabular}

Disponibilidade para esclarecer dúvidas e solucionar dificuldades dos alunos, relacionadas ao conteúdo da disciplina

\begin{tabular}{|c|c|c|c|c|c|}
\hline Ano_Semestre & \multicolumn{5}{|c|}{ Nota } \\
\hline 2003_01 & $12 \%$ & $39 \%$ & $45 \%$ & $4 \%$ & $100 \%$ \\
\hline 2006_02 & $11 \%$ & $39 \%$ & $46 \%$ & $5 \%$ & $100 \%$ \\
\hline 2007_02 & $10 \%$ & $41 \%$ & $45 \%$ & $5 \%$ & $100 \%$ \\
\hline 2008_01 & $10 \%$ & $40 \%$ & $45 \%$ & $4 \%$ & $100 \%$ \\
\hline 2008_02 & $11 \%$ & $41 \%$ & $44 \%$ & $5 \%$ & $100 \%$ \\
\hline 2009_01 & $11 \%$ & $40 \%$ & $44 \%$ & $5 \%$ & $100 \%$ \\
\hline Total & $11 \%$ & $40 \%$ & $45 \%$ & $4 \%$ & $100 \%$ \\
\hline
\end{tabular}

Cordialidade na relação com os alunos

\begin{tabular}{|c|c|c|c|c|c|}
\hline Ano_Semestre & \multicolumn{5}{|c|}{ Nota } \\
\hline 2003_01 & $9 \%$ & $26 \%$ & $63 \%$ & $2 \%$ & $100 \%$ \\
\hline 2006_02 & $8 \%$ & $27 \%$ & $64 \%$ & $1 \%$ & $100 \%$ \\
\hline 2007_02 & $9 \%$ & $29 \%$ & $61 \%$ & $1 \%$ & $100 \%$ \\
\hline 2008_01 & $10 \%$ & $28 \%$ & $62 \%$ & $1 \%$ & $100 \%$ \\
\hline 2008_02 & $10 \%$ & $29 \%$ & $60 \%$ & $1 \%$ & $100 \%$ \\
\hline 2009_01 & $9 \%$ & $29 \%$ & $62 \%$ & $1 \%$ & $100 \%$ \\
\hline Total & $9 \%$ & $28 \%$ & $62 \%$ & $1 \%$ & $100 \%$ \\
\hline
\end{tabular}

Respeito às idéias manifestadas pelos alunos acerca dos temas abordados 


\begin{tabular}{|c|c|c|c|c|c|}
\hline Ano_Semestre & \multicolumn{5}{|c|}{ Nota } \\
\hline 2003_01 & $8 \%$ & $30 \%$ & $59 \%$ & $3 \%$ & $100 \%$ \\
\hline 2006_02 & $8 \%$ & $30 \%$ & $60 \%$ & $2 \%$ & $100 \%$ \\
\hline 2007_02 & $8 \%$ & $31 \%$ & $59 \%$ & $2 \%$ & $100 \%$ \\
\hline 2008_01 & $9 \%$ & $30 \%$ & $59 \%$ & $2 \%$ & $100 \%$ \\
\hline 2008_02 & $8 \%$ & $31 \%$ & $58 \%$ & $2 \%$ & $100 \%$ \\
\hline 2009_01 & $8 \%$ & $30 \%$ & $59 \%$ & $2 \%$ & $100 \%$ \\
\hline Total & $8 \%$ & $31 \%$ & $59 \%$ & $2 \%$ & $100 \%$ \\
\hline
\end{tabular}

Disponibilidade para atendimento extra-classe

\begin{tabular}{|c|c|c|c|c|c|}
\hline Ano_Semestre & \multicolumn{5}{|c|}{ Nota } \\
\hline 2003_01 & $18 \%$ & $39 \%$ & $32 \%$ & $10 \%$ & $100 \%$ \\
\hline 2006_02 & $16 \%$ & $36 \%$ & $32 \%$ & $16 \%$ & $100 \%$ \\
\hline 2007_02 & $15 \%$ & $38 \%$ & $30 \%$ & $17 \%$ & $100 \%$ \\
\hline 2008_01 & $15 \%$ & $37 \%$ & $31 \%$ & $16 \%$ & $100 \%$ \\
\hline 2008_02 & $16 \%$ & $38 \%$ & $31 \%$ & $16 \%$ & $100 \%$ \\
\hline 2009_01 & $15 \%$ & $38 \%$ & $32 \%$ & $15 \%$ & $100 \%$ \\
\hline Total & $16 \%$ & $38 \%$ & $31 \%$ & $15 \%$ & $100 \%$ \\
\hline
\end{tabular}

Cumprimento dos horários de início e término das aulas, pelo professor

\begin{tabular}{|c|c|c|c|c|c|}
\hline Ano_Semestre & \multicolumn{5}{|c|}{ Nota } \\
\hline 2003_01 & $\begin{array}{l}12 \% \\
\end{array}$ & $28 \%$ & $58 \%$ & $3 \%$ & $100 \%$ \\
\hline 2006_02 & $12 \%$ & $29 \%$ & $58 \%$ & $1 \%$ & $100 \%$ \\
\hline 2007_02 & $11 \%$ & $30 \%$ & $57 \%$ & $1 \%$ & $100 \%$ \\
\hline 2008_01 & $11 \%$ & $30 \%$ & $57 \%$ & $2 \%$ & $100 \%$ \\
\hline 2008_02 & $12 \%$ & $30 \%$ & $56 \%$ & $2 \%$ & $100 \%$ \\
\hline 2009_01 & $10 \%$ & $30 \%$ & $58 \%$ & $2 \%$ & $100 \%$ \\
\hline Total & $11 \%$ & $30 \%$ & $57 \%$ & $2 \%$ & $100 \%$ \\
\hline
\end{tabular}

Assiduidade

\begin{tabular}{|c|c|c|c|c|c|}
\hline Ano_Semestre & 0 a 6 & 7 a 8 & $\begin{array}{c}\text { Nota } \\
9 \text { a } 10 \\
\end{array}$ & $\mathrm{~m}$ is & Total \\
\hline 2003_01 & $7 \%$ & $21 \%$ & $69 \%$ & $3 \%$ & $100 \%$ \\
\hline 2006_02 & $7 \%$ & $23 \%$ & $69 \%$ & $2 \%$ & $100 \%$ \\
\hline 2007_02 & $7 \%$ & $24 \%$ & $67 \%$ & $2 \%$ & $100 \%$ \\
\hline 2008_01 & $7 \%$ & $23 \%$ & $67 \%$ & $2 \%$ & $100 \%$ \\
\hline 2008_02 & $8 \%$ & $25 \%$ & $65 \%$ & $2 \%$ & $100 \%$ \\
\hline 2009_01 & $6 \%$ & $25 \%$ & $66 \%$ & $3 \%$ & $100 \%$ \\
\hline Total & $7 \%$ & $24 \%$ & $67 \%$ & $2 \%$ & $100 \%$ \\
\hline
\end{tabular}

\section{Apêndice D - tabelas cluster muito satisfeito}

Domínio do conteúdo ministrado 


\begin{tabular}{|c|c|c|c|c|c|}
\hline Ano_Semestre & \multicolumn{5}{|c|}{ Nota } \\
\hline 2003_01 & $0 \%$ & $2 \%$ & $97 \%$ & $1 \%$ & $100 \%$ \\
\hline 2006_02 & $0 \%$ & $2 \%$ & $98 \%$ & $0 \%$ & $100 \%$ \\
\hline 2007_02 & $0 \%$ & $2 \%$ & $98 \%$ & $1 \%$ & $100 \%$ \\
\hline 2008_01 & $0 \%$ & $2 \%$ & $98 \%$ & $1 \%$ & $100 \%$ \\
\hline 2008_02 & $0 \%$ & $2 \%$ & $98 \%$ & $1 \%$ & $100 \%$ \\
\hline 2009_01 & $0 \%$ & $2 \%$ & $97 \%$ & $1 \%$ & $100 \%$ \\
\hline Total & $0 \%$ & $2 \%$ & $98 \%$ & $1 \%$ & $100 \%$ \\
\hline
\end{tabular}

Qualidade na transmissão do conteúdo

\begin{tabular}{|c|c|c|c|c|c|}
\hline Ano_Semestre & \multicolumn{5}{|c|}{ Nota } \\
\hline 2003_01 & $0 \%$ & $5 \%$ & $94 \%$ & $1 \%$ & $100 \%$ \\
\hline 2006_02 & $0 \%$ & $4 \%$ & $95 \%$ & $1 \%$ & $100 \%$ \\
\hline 2007_02 & $0 \%$ & $5 \%$ & $95 \%$ & $1 \%$ & $100 \%$ \\
\hline 2008_01 & $0 \%$ & $5 \%$ & $95 \%$ & $0 \%$ & $100 \%$ \\
\hline 2008_02 & $0 \%$ & $5 \%$ & $94 \%$ & $1 \%$ & $100 \%$ \\
\hline 2009_01 & $0 \%$ & $5 \%$ & $94 \%$ & $1 \%$ & $100 \%$ \\
\hline Total & $0 \%$ & $5 \%$ & $94 \%$ & $1 \%$ & $100 \%$ \\
\hline
\end{tabular}

Entusiasmo demonstrado na transmissão do conteúdo

\begin{tabular}{|c|c|c|c|c|c|}
\hline Ano_Semestre & 0 a 6 & 7 a 8 & $\begin{array}{c}\text { Nota } \\
9 \text { a } 10\end{array}$ & $\mathrm{~m}$ is & Total \\
\hline 2003_01 & $0 \%$ & $3 \%$ & $96 \%$ & $1 \%$ & $100 \%$ \\
\hline 2006_02 & $0 \%$ & $3 \%$ & $97 \%$ & $1 \%$ & $100 \%$ \\
\hline 2007_02 & $0 \%$ & $3 \%$ & $96 \%$ & $1 \%$ & $100 \%$ \\
\hline 2008_01 & $0 \%$ & $3 \%$ & $96 \%$ & $1 \%$ & $100 \%$ \\
\hline 2008_02 & $0 \%$ & $3 \%$ & $97 \%$ & $1 \%$ & $100 \%$ \\
\hline 2009_01 & $0 \%$ & $3 \%$ & $96 \%$ & $1 \%$ & $100 \%$ \\
\hline Total & $0 \%$ & $3 \%$ & $96 \%$ & $1 \%$ & $100 \%$ \\
\hline
\end{tabular}

Incentivo à participação dos alunos nas atividades previstas no programa da disciplina

\begin{tabular}{|c|c|c|c|c|c|}
\hline Ano_Semestre & 0 a 6 & 7 a 8 & $\begin{array}{c}\text { Nota } \\
9 \text { a } 10 \\
\end{array}$ & $\mathrm{~m}$ is & Total \\
\hline 2003_01 & $0 \%$ & $6 \%$ & $93 \%$ & $2 \%$ & $100 \%$ \\
\hline 2006_02 & $0 \%$ & $5 \%$ & $93 \%$ & $1 \%$ & $100 \%$ \\
\hline 2007_02 & $0 \%$ & $5 \%$ & $94 \%$ & $1 \%$ & $100 \%$ \\
\hline 2008_01 & $0 \%$ & $5 \%$ & $94 \%$ & $1 \%$ & $100 \%$ \\
\hline 2008_02 & $0 \%$ & $5 \%$ & $94 \%$ & $1 \%$ & $100 \%$ \\
\hline 2009_01 & $0 \%$ & $5 \%$ & $93 \%$ & $2 \%$ & $100 \%$ \\
\hline Total & $0 \%$ & $5 \%$ & $94 \%$ & $1 \%$ & $100 \%$ \\
\hline
\end{tabular}

Incentivo, ao aluno, à realização de atividades adicionais de aprofundamento do aprendizado 


\begin{tabular}{|c|c|c|c|c|c|}
\hline Ano_Semestre & \multicolumn{4}{|c|}{ Nota } & Total \\
\hline 2003_01 & $1 \%$ & $13 \%$ & $83 \%$ & $3 \%$ & $100 \%$ \\
\hline 2006_02 & $0 \%$ & $11 \%$ & $85 \%$ & $3 \%$ & $100 \%$ \\
\hline 2007_02 & $0 \%$ & $11 \%$ & $86 \%$ & $3 \%$ & $100 \%$ \\
\hline 2008_01 & $0 \%$ & $11 \%$ & $86 \%$ & $3 \%$ & $100 \%$ \\
\hline 2008_02 & $0 \%$ & $11 \%$ & $86 \%$ & $3 \%$ & $100 \%$ \\
\hline 2009_01 & $0 \%$ & $11 \%$ & $86 \%$ & $3 \%$ & $100 \%$ \\
\hline Total & $0 \%$ & $11 \%$ & $86 \%$ & $3 \%$ & $100 \%$ \\
\hline
\end{tabular}

Uso de estratégias para motivar os alunos em relação ao conteúdo

\begin{tabular}{|c|c|c|c|c|c|}
\hline Ano_Semestre & 0 a 6 & 7 a 8 & $\begin{array}{c}\text { Nota } \\
9 \text { a } 10\end{array}$ & $\mathrm{~m}$ is & Total \\
\hline 2003_01 & $0 \%$ & $15 \%$ & $83 \%$ & $2 \%$ & $100 \%$ \\
\hline 2006_02 & $0 \%$ & $13 \%$ & $85 \%$ & $2 \%$ & $100 \%$ \\
\hline 2007_02 & $0 \%$ & $13 \%$ & $85 \%$ & $2 \%$ & $100 \%$ \\
\hline 2008_01 & $0 \%$ & $13 \%$ & $85 \%$ & $1 \%$ & $100 \%$ \\
\hline 2008_02 & $0 \%$ & $13 \%$ & $85 \%$ & $2 \%$ & $100 \%$ \\
\hline 2009_01 & $0 \%$ & $13 \%$ & $85 \%$ & $2 \%$ & $100 \%$ \\
\hline Total & $0 \%$ & $13 \%$ & $85 \%$ & $2 \%$ & $100 \%$ \\
\hline
\end{tabular}

Ritmo de apresentação do conteúdo

\begin{tabular}{|c|c|c|c|c|c|}
\hline Ano_Semestre & 0 a 6 & 7 a 8 & $\begin{array}{c}\text { Nota } \\
9 \text { a } 10\end{array}$ & $\mathrm{~m}$ is & Total \\
\hline 2003_01 & $1 \%$ & $12 \%$ & $84 \%$ & $2 \%$ & $100 \%$ \\
\hline 2006_02 & $1 \%$ & $12 \%$ & $86 \%$ & $1 \%$ & $100 \%$ \\
\hline 2007_02 & $1 \%$ & $11 \%$ & $88 \%$ & $1 \%$ & $100 \%$ \\
\hline 2008_01 & $1 \%$ & $11 \%$ & $88 \%$ & $1 \%$ & $100 \%$ \\
\hline 2008_02 & $1 \%$ & $11 \%$ & $88 \%$ & $1 \%$ & $100 \%$ \\
\hline 2009_01 & $1 \%$ & $11 \%$ & $87 \%$ & $1 \%$ & $100 \%$ \\
\hline Total & $1 \%$ & $11 \%$ & $87 \%$ & $1 \%$ & $100 \%$ \\
\hline
\end{tabular}

Adequação das atividades desenvolvidas para o alcance dos objetivos propostos

\begin{tabular}{|c|c|c|c|c|c|}
\hline Ano_Semestre & \multicolumn{5}{|c|}{ Nota } \\
\hline 2003_01 & $0 \%$ & $6 \%$ & $92 \%$ & $2 \%$ & $100 \%$ \\
\hline 2006_02 & $0 \%$ & $5 \%$ & $94 \%$ & $1 \%$ & $100 \%$ \\
\hline 2007_02 & $0 \%$ & $5 \%$ & $94 \%$ & $1 \%$ & $100 \%$ \\
\hline 2008_01 & $0 \%$ & $5 \%$ & $94 \%$ & $1 \%$ & $100 \%$ \\
\hline 2008_02 & $0 \%$ & $5 \%$ & $94 \%$ & $1 \%$ & $100 \%$ \\
\hline 2009_01 & $0 \%$ & $5 \%$ & $94 \%$ & $1 \%$ & $100 \%$ \\
\hline Total & $0 \%$ & $5 \%$ & $94 \%$ & $1 \%$ & $100 \%$ \\
\hline
\end{tabular}

Profundidade com que o conteúdo foi abordado, considerando os objetivos da disciplina 


\begin{tabular}{|c|c|c|c|c|c|}
\hline Ano_Semestre & \multicolumn{5}{|c|}{ Nota } \\
\hline 2003_01 & $0 \%$ & $8 \%$ & $90 \%$ & $2 \%$ & $100 \%$ \\
\hline 2006_02 & $0 \%$ & $7 \%$ & $91 \%$ & $1 \%$ & $100 \%$ \\
\hline 2007_02 & $0 \%$ & $7 \%$ & $92 \%$ & $1 \%$ & $100 \%$ \\
\hline 2008_01 & $0 \%$ & $7 \%$ & $92 \%$ & $1 \%$ & $100 \%$ \\
\hline 2008_02 & $0 \%$ & $7 \%$ & $92 \%$ & $1 \%$ & $100 \%$ \\
\hline 2009_01 & $0 \%$ & $6 \%$ & $92 \%$ & $1 \%$ & $100 \%$ \\
\hline Total & $0 \%$ & $7 \%$ & $91 \%$ & $1 \%$ & $100 \%$ \\
\hline
\end{tabular}

Integração do conteúdo da disciplina com conteúdos conexos de outras disciplinas

\begin{tabular}{|c|c|c|c|c|c|}
\hline Ano_Semestre & \multicolumn{5}{|c|}{ Nota } \\
\hline 2003_01 & $1 \%$ & $13 \%$ & $82 \%$ & $5 \%$ & $100 \%$ \\
\hline 2006_02 & $1 \%$ & $12 \%$ & $83 \%$ & $4 \%$ & $100 \%$ \\
\hline 2007_02 & $1 \%$ & $10 \%$ & $86 \%$ & $4 \%$ & $100 \%$ \\
\hline 2008_01 & $1 \%$ & $10 \%$ & $86 \%$ & $3 \%$ & $100 \%$ \\
\hline 2008_02 & $1 \%$ & $10 \%$ & $86 \%$ & $4 \%$ & $100 \%$ \\
\hline 2009_01 & $1 \%$ & $10 \%$ & $86 \%$ & $4 \%$ & $100 \%$ \\
\hline Total & $1 \%$ & $10 \%$ & $85 \%$ & $4 \%$ & $100 \%$ \\
\hline
\end{tabular}

Integração entre teoria, pesquisa e/ou aspectos da realidade

\begin{tabular}{|c|c|c|c|c|c|}
\hline Ano_Semestre & 0 a 6 & 7 a 8 & $\begin{array}{c}\text { Nota } \\
9 \text { a } 10\end{array}$ & $\mathrm{~m}$ is & Total \\
\hline 2003_01 & $0 \%$ & $10 \%$ & $85 \%$ & $5 \%$ & $100 \%$ \\
\hline 2006_02 & $0 \%$ & $8 \%$ & $87 \%$ & $4 \%$ & $100 \%$ \\
\hline 2007_02 & $0 \%$ & $8 \%$ & $88 \%$ & $4 \%$ & $100 \%$ \\
\hline 2008_01 & $0 \%$ & $7 \%$ & $89 \%$ & $4 \%$ & $100 \%$ \\
\hline 2008_02 & $0 \%$ & $7 \%$ & $88 \%$ & $4 \%$ & $100 \%$ \\
\hline 2009_01 & $0 \%$ & $8 \%$ & $88 \%$ & $4 \%$ & $100 \%$ \\
\hline Total & $0 \%$ & $8 \%$ & $88 \%$ & $4 \%$ & $100 \%$ \\
\hline
\end{tabular}

Qualidade dos exemplos utilizados para relacionar teoria, pesquisa e prática

\begin{tabular}{|c|c|c|c|c|c|}
\hline Ano_Semestre & \multicolumn{5}{|c|}{ Nota } \\
\hline 2003_01 & $0 \%$ & $6 \%$ & $89 \%$ & $4 \%$ & $100 \%$ \\
\hline 2006_02 & $0 \%$ & $5 \%$ & $92 \%$ & $3 \%$ & $100 \%$ \\
\hline 2007_02 & $0 \%$ & $5 \%$ & $92 \%$ & $4 \%$ & $100 \%$ \\
\hline 2008_01 & $0 \%$ & $5 \%$ & $93 \%$ & $3 \%$ & $100 \%$ \\
\hline 2008_02 & $0 \%$ & $5 \%$ & $92 \%$ & $3 \%$ & $100 \%$ \\
\hline 2009_01 & $0 \%$ & $5 \%$ & $92 \%$ & $3 \%$ & $100 \%$ \\
\hline Total & $0 \%$ & $5 \%$ & $92 \%$ & $3 \%$ & $100 \%$ \\
\hline
\end{tabular}

Coerência entre nível de complexidade das avaliações e o conteúdo ministrado 


\begin{tabular}{|c|c|c|c|c|c|}
\hline Ano_Semestre & \multicolumn{4}{|c|}{ Nota } & Total \\
\hline 2003_01 & $1 \%$ & $9 \%$ & $86 \%$ & $5 \%$ & $100 \%$ \\
\hline 2006_02 & $1 \%$ & $7 \%$ & $90 \%$ & $2 \%$ & $100 \%$ \\
\hline 2007_02 & $1 \%$ & $7 \%$ & $90 \%$ & $2 \%$ & $100 \%$ \\
\hline 2008_01 & $0 \%$ & $7 \%$ & $91 \%$ & $2 \%$ & $100 \%$ \\
\hline 2008_02 & $1 \%$ & $7 \%$ & $90 \%$ & $2 \%$ & $100 \%$ \\
\hline 2009_01 & $1 \%$ & $7 \%$ & $90 \%$ & $2 \%$ & $100 \%$ \\
\hline Total & $1 \%$ & $7 \%$ & $90 \%$ & $2 \%$ & $100 \%$ \\
\hline
\end{tabular}

Discussão dos resultados de avaliações de aprendizagem

\begin{tabular}{|c|c|c|c|c|c|}
\hline Ano_Semestre & 0 a 6 & 7 a 8 & $\begin{array}{c}\text { Nota } \\
9 \text { a } 10\end{array}$ & $\mathrm{~m}$ is & Total \\
\hline 2003_01 & $3 \%$ & $17 \%$ & $73 \%$ & $8 \%$ & $100 \%$ \\
\hline 2006_02 & $2 \%$ & $12 \%$ & $80 \%$ & $6 \%$ & $100 \%$ \\
\hline 2007_02 & $2 \%$ & $11 \%$ & $82 \%$ & $5 \%$ & $100 \%$ \\
\hline 2008_01 & $2 \%$ & $12 \%$ & $81 \%$ & $5 \%$ & $100 \%$ \\
\hline 2008_02 & $2 \%$ & $12 \%$ & $81 \%$ & $5 \%$ & $100 \%$ \\
\hline 2009_01 & $2 \%$ & $11 \%$ & $81 \%$ & $6 \%$ & $100 \%$ \\
\hline Total & $2 \%$ & $12 \%$ & $80 \%$ & $6 \%$ & $100 \%$ \\
\hline
\end{tabular}

Adequação do uso dos recursos de ensino

\begin{tabular}{|c|c|c|c|c|c|}
\hline Ano_Semestre & 0 a 6 & 7 a 8 & $\begin{array}{c}\text { Nota } \\
9 \text { a } 10\end{array}$ & $\mathrm{~m}$ is & Total \\
\hline 2003_01 & $2 \%$ & $14 \%$ & $78 \%$ & $6 \%$ & $100 \%$ \\
\hline 2006_02 & $1 \%$ & $12 \%$ & $81 \%$ & $5 \%$ & $100 \%$ \\
\hline 2007_02 & $1 \%$ & $10 \%$ & $85 \%$ & $4 \%$ & $100 \%$ \\
\hline 2008_01 & $1 \%$ & $10 \%$ & $85 \%$ & $3 \%$ & $100 \%$ \\
\hline 2008_02 & $1 \%$ & $10 \%$ & $84 \%$ & $4 \%$ & $100 \%$ \\
\hline 2009_01 & $1 \%$ & $9 \%$ & $85 \%$ & $4 \%$ & $100 \%$ \\
\hline Total & $1 \%$ & $11 \%$ & $84 \%$ & $4 \%$ & $100 \%$ \\
\hline
\end{tabular}

Disponibilidade para esclarecer dúvidas e solucionar dificuldades dos alunos, relacionadas ao conteúdo da disciplina

\begin{tabular}{|c|c|c|c|c|c|}
\hline Ano_Semestre & \multicolumn{5}{|c|}{ Nota } \\
\hline 2003_01 & $0 \%$ & $7 \%$ & $90 \%$ & $3 \%$ & $100 \%$ \\
\hline 2006_02 & $0 \%$ & $6 \%$ & $91 \%$ & $2 \%$ & $100 \%$ \\
\hline 2007_02 & $0 \%$ & $5 \%$ & $92 \%$ & $2 \%$ & $100 \%$ \\
\hline 2008_01 & $0 \%$ & $5 \%$ & $92 \%$ & $2 \%$ & $100 \%$ \\
\hline 2008_02 & $0 \%$ & $5 \%$ & $92 \%$ & $3 \%$ & $100 \%$ \\
\hline 2009_01 & $0 \%$ & $5 \%$ & $92 \%$ & $3 \%$ & $100 \%$ \\
\hline Total & $0 \%$ & $6 \%$ & $92 \%$ & $3 \%$ & $100 \%$ \\
\hline
\end{tabular}

Cordialidade na relação com os alunos 


\begin{tabular}{|c|c|c|c|c|c|}
\hline Ano_Semestre & \multicolumn{4}{|c|}{ Nota } & Total \\
\hline 2003_01 & $0 \%$ & $4 \%$ & $94 \%$ & $1 \%$ & $100 \%$ \\
\hline 2006_02 & $1 \%$ & $4 \%$ & $95 \%$ & $1 \%$ & $100 \%$ \\
\hline 2007_02 & $0 \%$ & $5 \%$ & $94 \%$ & $1 \%$ & $100 \%$ \\
\hline 2008_01 & $1 \%$ & $4 \%$ & $95 \%$ & $1 \%$ & $100 \%$ \\
\hline 2008_02 & $1 \%$ & $5 \%$ & $94 \%$ & $1 \%$ & $100 \%$ \\
\hline 2009_01 & $0 \%$ & $4 \%$ & $94 \%$ & $1 \%$ & $100 \%$ \\
\hline Total & $1 \%$ & $4 \%$ & $95 \%$ & $1 \%$ & $100 \%$ \\
\hline
\end{tabular}

Respeito às idéias manifestadas pelos alunos acerca dos temas abordados

\begin{tabular}{|c|c|c|c|c|c|}
\hline Ano_Semestre & \multicolumn{5}{|c|}{ Nota } \\
\hline 2003_01 & $0 \%$ & $4 \%$ & $93 \%$ & $3 \%$ & $100 \%$ \\
\hline 2006_02 & $0 \%$ & $4 \%$ & $95 \%$ & $1 \%$ & $100 \%$ \\
\hline 2007_02 & $0 \%$ & $4 \%$ & $94 \%$ & $1 \%$ & $100 \%$ \\
\hline 2008_01 & $1 \%$ & $4 \%$ & $95 \%$ & $1 \%$ & $100 \%$ \\
\hline 2008_02 & $0 \%$ & $4 \%$ & $94 \%$ & $1 \%$ & $100 \%$ \\
\hline 2009_01 & $0 \%$ & $4 \%$ & $94 \%$ & $1 \%$ & $100 \%$ \\
\hline Total & $0 \%$ & $4 \%$ & $94 \%$ & $1 \%$ & $100 \%$ \\
\hline
\end{tabular}

Disponibilidade para atendimento extra-classe

\begin{tabular}{|c|c|c|c|c|c|}
\hline Ano_Semestre & \multicolumn{5}{|c|}{ Nota } \\
\hline 2003_01 & $2 \%$ & $13 \%$ & $77 \%$ & $8 \%$ & $100 \%$ \\
\hline 2006_02 & $2 \%$ & $11 \%$ & $76 \%$ & $11 \%$ & $100 \%$ \\
\hline 2007_02 & $1 \%$ & $11 \%$ & $77 \%$ & $11 \%$ & $100 \%$ \\
\hline 2008_01 & $1 \%$ & $11 \%$ & $78 \%$ & $10 \%$ & $100 \%$ \\
\hline 2008_02 & $2 \%$ & $11 \%$ & $77 \%$ & $10 \%$ & $100 \%$ \\
\hline 2009_01 & $1 \%$ & $10 \%$ & $78 \%$ & $10 \%$ & $100 \%$ \\
\hline Total & $2 \%$ & $11 \%$ & $77 \%$ & $10 \%$ & $100 \%$ \\
\hline
\end{tabular}

Cumprimento dos horários de início e término das aulas, pelo professor

\begin{tabular}{|c|c|c|c|c|c|}
\hline Ano_Semestre & 0 a 6 & 7 a 8 & $\begin{array}{c}\text { Nota } \\
9 \text { a } 10 \\
\end{array}$ & $\mathrm{~m}$ is & Total \\
\hline 2003_01 & $2 \%$ & $8 \%$ & $88 \%$ & $2 \%$ & $100 \%$ \\
\hline 2006_02 & $1 \%$ & $8 \%$ & $90 \%$ & $1 \%$ & $100 \%$ \\
\hline 2007_02 & $1 \%$ & $7 \%$ & $90 \%$ & $1 \%$ & $100 \%$ \\
\hline 2008_01 & $1 \%$ & $7 \%$ & $91 \%$ & $1 \%$ & $100 \%$ \\
\hline 2008_02 & $1 \%$ & $7 \%$ & $90 \%$ & $1 \%$ & $100 \%$ \\
\hline 2009_01 & $1 \%$ & $7 \%$ & $90 \%$ & $2 \%$ & $100 \%$ \\
\hline Total & $1 \%$ & $7 \%$ & $90 \%$ & $1 \%$ & $100 \%$ \\
\hline
\end{tabular}

Assiduidade 


\begin{tabular}{|c|c|c|c|c|c|}
\hline \multirow{2}{*}{ Ano_Semestre } & \multicolumn{5}{|c|}{ Nota } \\
\hline & 0 a 6 & 7 a 8 & 9 a 10 & $\mathrm{~m}$ is & Total \\
\hline 2003_01 & $1 \%$ & $5 \%$ & $92 \%$ & $2 \%$ & $100 \%$ \\
\hline 2006_02 & $1 \%$ & $5 \%$ & $93 \%$ & $1 \%$ & $100 \%$ \\
\hline 2007_02 & $1 \%$ & $5 \%$ & $93 \%$ & $1 \%$ & $100 \%$ \\
\hline 2008_01 & $1 \%$ & $5 \%$ & $93 \%$ & $1 \%$ & $100 \%$ \\
\hline 2008_02 & $1 \%$ & $5 \%$ & $93 \%$ & $1 \%$ & $100 \%$ \\
\hline 2009_01 & $1 \%$ & $5 \%$ & $93 \%$ & $2 \%$ & $100 \%$ \\
\hline Total & $1 \%$ & $5 \%$ & $93 \%$ & $2 \%$ & $100 \%$ \\
\hline
\end{tabular}




\section{ANEXO A - AVALIAÇÃO DE DISCIPLINA PELO ALUNO}

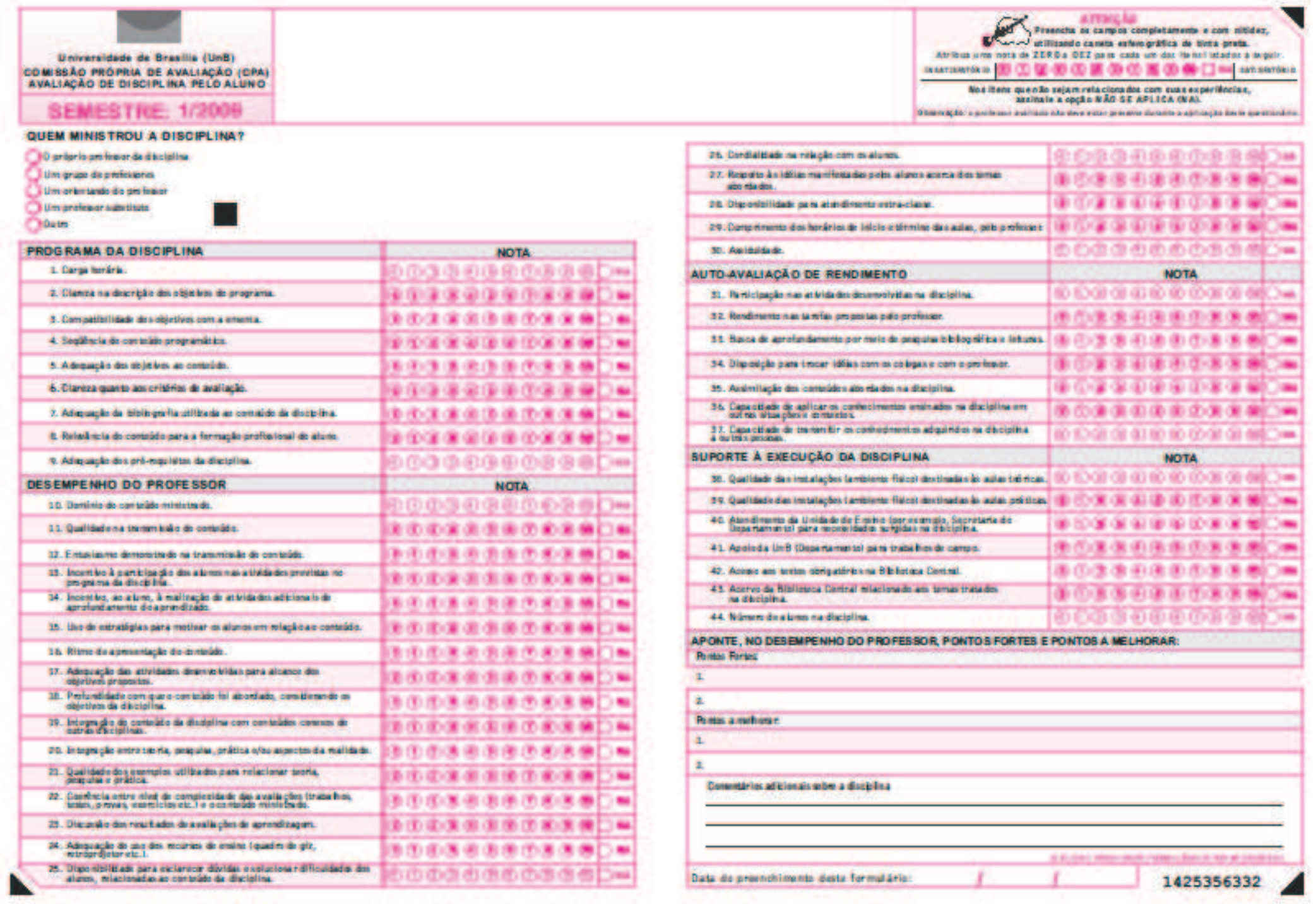




\section{ANEXO B - LEI $n^{\circ} 9.394$}

De acordo com a lei $n^{\circ}$ 9.394, de 20 de dezembro de 1996, capitulo IV Art. 43 a educação superior tem por finalidade:

I - estimular a criação cultural e o desenvolvimento do espírito científico e do pensamento reflexivo;

II - formar diplomados nas diferentes áreas de conhecimento, aptos para a inserção em setores profissionais e para a participação no desenvolvimento da sociedade brasileira, e colaborar na sua formação contínua;

III - incentivar o trabalho de pesquisa e investigação científica, visando o desenvolvimento da ciência e da tecnologia e da criação e difusão da cultura, e, desse modo, desenvolver o entendimento do homem e do meio em que vive;

IV - promover a divulgação de conhecimentos culturais, científicos e técnicos que constituem patrimônio da humanidade e comunicar o saber através do ensino, de publicações ou de outras formas de comunicação;

$\mathrm{V}$ - suscitar o desejo permanente de aperfeiçoamento cultural e profissional e possibilitar a correspondente concretização, integrando os conhecimentos que vão sendo adquiridos numa estrutura intelectual sistematizadora do conhecimento de cada geração;

VI - estimular o conhecimento dos problemas do mundo presente, em particular os nacionais e regionais, prestar serviços especializados à comunidade e estabelecer com esta uma relação de reciprocidade;

VII - promover a extensão, aberta à participação da população, visando à difusão das conquistas e benefícios resultantes da criação cultural e da pesquisa científica e tecnológica geradas na instituição. 